\title{
Cross-calibration of S-NPP VIIRS moderate-resolution reflective solar bands against MODIS Aqua over dark water scenes
}

\author{
Andrew M. Sayer ${ }^{1,2}$, N. Christina Hsu ${ }^{2}$, Corey Bettenhausen ${ }^{2,3}$, Robert E. Holz ${ }^{4}$, Jaehwa Lee ${ }^{2,5}$, Greg Quinn ${ }^{4}$, and \\ Paolo Veglio 4 \\ ${ }^{1}$ Goddard Earth Sciences Technology And Research (GESTAR), Universities Space Research Association \\ (USRA), Columbia, MD, USA \\ ${ }^{2}$ NASA Goddard Space Flight Center, Greenbelt, MD, USA \\ ${ }^{3}$ Adnet Systems, Inc, Bethesda, MD, USA \\ ${ }^{4}$ Space Science and Engineering Center, University of Wisconsin, Madison, WI, USA \\ ${ }^{5}$ Earth Systems Science Interdisciplinary Center (ESSIC), University of Maryland, College Park, MD, USA \\ Correspondence to: Andrew M. Sayer (andrew.sayer@nasa.gov)
}

Received: 15 July 2016 - Discussion started: 17 August 2016

Revised: 23 March 2017 - Accepted: 24 March 2017 - Published: 13 April 2017

\begin{abstract}
The Visible Infrared Imaging Radiometer Suite (VIIRS) is being used to continue the record of Earth Science observations and data products produced routinely from $\mathrm{Na}-$ tional Aeronautics and Space Administration (NASA) Moderate Resolution Imaging Spectroradiometer (MODIS) measurements. However, the absolute calibration of VIIRS's reflected solar bands is thought to be biased, leading to offsets in derived data products such as aerosol optical depth (AOD) as compared to when similar algorithms are applied to different sensors. This study presents a cross-calibration of these VIIRS bands against MODIS Aqua over dark water scenes, finding corrections to the NASA VIIRS Level 1 (version 2) reflectances between approximately +1 and $-7 \%$ (dependent on band) are needed to bring the two into alignment (after accounting for expected differences resulting from different band spectral response functions), and indications of relative trending of up to $\sim 0.35 \%$ per year in some bands. The derived calibration gain corrections are also applied to the VIIRS reflectance and then used in an AOD retrieval, and they are shown to decrease the bias and total error in AOD across the mid-visible spectral region compared to the standard VIIRS NASA reflectance calibration. The resulting AOD bias characteristics are similar to those of NASA MODIS AOD data products, which is encouraging in terms of multi-sensor data continuity.
\end{abstract}

\section{Introduction}

Launched in late 2011, the Suomi National Polar-Orbiting Partnership (S-NPP) satellite is a precursor to the Joint Polar Satellite System (JPSS), which represents the next generation of the USA's operational Earth observation satellites. One of the instruments aboard S-NPP (and the JPSS series) is the Visible Infrared Imaging Radiometer Suite (VIIRS; Cao et al., 2013, 2014), designed to continue the types of observations made by the Defence Meteorological Satellite Program (DMSP) Advanced Very High Resolution Radiometers (AVHRR, data record 1978 onwards) and Earth Observing System (EOS) sensors such as the Sea-viewing Wide Field-of-view Sensor (SeaWiFS, 1997 2010) and Terra/Aqua Moderate Resolution Imaging Spectroradiometers (MODIS, 2000 onwards). All of these instruments are passive broad-swath imaging radiometers, measuring top of atmosphere (TOA) radiance in a set of reflective solar bands (RSBs) and (except SeaWiFS) thermal emissive bands (TEBs).

Data from DMSP and EOS-era instruments have been used for a broad variety of Earth science applications, including the study of tropospheric aerosols, and a number of algorithms have been developed to create aerosol optical depth (AOD) data products from these sensors over both land (e.g. Hsu et al., 2004; Levy et al., 2007; Lyapustin et al., 2011) and water (e.g. Stowe et al., 1997; Tanré et al., 1997; 
Mishchenko et al., 1999; Ahmad et al., 2010; Sayer et al., 2012a) surfaces. In all these algorithms, aerosol information is determined using a subset of the available RSBs, while TEB data are used mainly for identifying pixels containing water or ice clouds. The measurement capabilities of VIIRS and MODIS are similar, which has motivated the adaptation of EOS-era National Aeronautics and Space Administration (NASA) algorithms to VIIRS, with the goal being to move toward a multi-sensor consistent long-term data record from a combination of MODIS and VIIRS measurements. In the case of AOD, VIIRS versions of the Satellite Ocean Aerosol Retrieval (SOAR) algorithm, applied previously to SeaWiFS observations over water (Sayer et al., 2012a), and the Deep Blue (DB) algorithm, applied previously to SeaWiFS and MODIS measurements over land (Hsu et al., 2013), are shortly to be released to the public. VIIRS versions of the MODIS "Dark Target" land algorithm, and over-water algorithm, are also in development (Levy et al., 2015).

The National Oceanic and Atmospheric Administration (NOAA) Interface Data Processing Segment (IDPS) also generates a number of data products from VIIRS in near-real time to support their operational needs, including AOD over oceans and dark land surfaces (Jackson et al., 2013); these are based on the same scientific principles to the NASA algorithms and have a similar data quality (Liu et al., 2014; Huang et al., 2016). However, the algorithms are not identical (hence have different contextual biases) and operate in forward-processing mode only. Thus as algorithm or calibration updates are made, discontinuities arise in the data records as data are not reprocessed retrospectively to provide a self-consistent time series. Both agencies also generate their own similar but slightly different Level 1 (L1; measured RSB reflectance/TEB radiance) data sets. L1 data are sometimes further denoted L1a (uncalibrated) or L1b (calibrated) data, although in practice additional corrections are sometimes applied to the "standard" L1b data before processing to geophysical data products (which are known as Level 2, L2), and so the term L1 is used here for simplicity.

VIIRS has similar on-board calibration capabilities to MODIS, and NASA L1 requirements for the RSBs are $2 \%$ accuracy in reflectance (for a reference scene brightness) and 2.5-3\% (dependent on band) polarisation sensitivity. Recent work (Xiong et al., 2016; Lei and Xiong, 2017) indicates that the trending of the radiometric calibration since launch in the NASA VIIRS L1 products remains well characterized. Trending is monitored using a solar diffuser (SD) and SD stability monitor (SDSM), together with periodic orbit manoeuvres to view the moon as another stable calibration source (Sun et al., 2007; Lei and Xiong, 2017). These data form the basis of the calibration applied in the NASA MODIS and VIIRS standard L1 data files, used in data processing by the Atmospheres and Land scientific discipline teams, and the analyses are performed routinely by the MODIS Characterization Support Team (MCST) and VIIRS Characterization Support Team (VCST); MCST and VCST (referred to as "NASA cal- ibration" for simplicity) are composed of many of the same people, leading to consistency in approach. Similarly, corrections to account for polarisation sensitivity, which are important for ocean colour studies and AOD retrievals using wavelengths in the blue spectral region, are fairly mature (e.g. Meister et al., 2005; Jeong et al., 2011; Meister and Franz, 2011; Sayer et al., 2015b).

However, the SD analyses account for only the drift in calibration through the mission (i.e. a relative trending) and do not address the absolute calibration. As mentioned above, NOAA IDPS operates in forward-processing only; various studies have indicated that early in the mission the IDPS products did not meet the desired RSB absolute calibration accuracy, suggesting calibration biases in excess of $5 \%$ in some cases, although at present in the IDPS products all bands are believed to meet performance goals following various calibration analyses and improvements (Cao et al., 2013, 2014; Uprety et al., 2013, 2014; Uprety and Cao, 2015; Wang and Cao, 2016). This has not yet been done for the NASA L1 products, which is a motivation for the present study. Depending on the magnitude and spectral correlation of calibration biases, significant offsets can be introduced in derived data sets such as AOD, sometimes larger than the $\sim 0.03$ often taken as a realistic minimum typical AOD retrieval uncertainty for low-AOD open-ocean scenes using this type of sensor (Sayer et al., 2012a; Lyapustin et al., 2014; Levy et al., 2015). These calibration discrepancies must therefore be reduced if the goal of a long-term aerosol data set with as consistent as possible error characteristics from the MODIS and VIIRS sensors is to be achieved.

These prior studies of VIIRS RSB absolute calibration have largely been performed by comparing nearsimultaneous observations from VIIRS and MODIS Aqua, typically over bright targets such as deserts, Dome $\mathrm{C}$ in Antarctica, or deep convective clouds. MODIS Aqua has been used as it is considered to have better absolute calibration than VIIRS and well-characterized stability (Toller et al., 2013; Wu et al., 2013; Lyapustin et al., 2014; Sayer et al., 2015b). Further, the two sensors' fields of view intersect on a regular basis. Even if MODIS Aqua's calibration is not perfect, tying VIIRS to MODIS Aqua does mean that any calibration-related biases in derived data sets should look similar in both sensors, thus increasing the level of data product consistency between the two.

Additionally, these studies have typically only considered a subset of VIIRS RSBs, excluding some which are required for the AOD retrieval algorithms which have been applied to EOS-era measurements. They used NOAA L1 data from the first few years of the VIIRS mission; these results may not necessarily be transferable to the NASA calibration, or to more recent years of observations, since the underlying L1 source data are not the same (and, as mentioned, various updates to the NOAA IDPS products have been made in forward-processing). The differences in derived calibration corrections over these different target types are in some 
cases non-negligible. This is likely due to some combination of the different versions of NOAA L1 products used, as well as difficulties accounting for the slight spectral and directional differences between MODIS and VIIRS observations over these diverse surface types. In some cases it is not documented exactly how differences between the sensors' spectral/directional characteristics were accounted for (i.e. whether discussed discrepancies include or exclude the level of difference expected due to sensor differences). Finally, the main focus of the majority of these prior studies is bright targets, while AOD retrieval is largely performed over dark scenes, and so residual forward model biases or nonlinearities in detector response may limit the applicability to dark scenes.

Absolute (whether direct or vicarious) calibration using an atmospheric correction ground data source such as Aerosol Robotic Network (AERONET; Holben et al., 1998) is another option, but this has a disadvantage of also calibrating out some forward radiative transfer model errors (i.e. derived calibration coefficients may not be transferable to other applications since they include biases in the radiative transfer model and/or retrieval algorithms as well as the sensor), which has the side effect of removing the independence of the calibration from the data source typically used to validate the derived geophysical data product (in this case, AOD). As one example, the NASA Ocean Biology Processing Group (OBPG) take a vicarious calibration approach, in which calibration gains are adjusted to make water-leaving radiance retrievals consistent with ground truth data, that is sensorindependent and results in a high level of inter-sensor data consistency but does mean that residual errors in the atmospheric correction algorithm propagate into derived vicarious gains (Franz et al., 2007); analysis of the resultant errors in the output AOD from the atmospheric correction process indicates that they are not negligible (Kahn et al., 2016). Additionally, at present the OBPG have not performed this analysis for the VIIRS near-infrared (NIR) and shortwave infrared (SWIR) bands (B. Franz and R. Eplee, personal communication, 2016). Thus, even though the OBPG analyses take the NASA L1 data from VCST as a basis, they cannot necessarily be used directly in other retrieval algorithms. Hlaing et al. (2014) performed an absolute calibration of some VIIRS bands (again, except SWIR) using ancillary AERONET Ocean Color (AERONET-OC) data, bypassing the retrieval stage of the OBPG calibration methodology (i.e. thus keeping the data independent of its validation data), although they found that the quality of this absolute calibration could be limited by the quality of aerosol constraints from the AERONET-OC data in clean conditions.

The purpose of this study is to describe a cross-calibration of L1 reflectance from S-NPP VIIRS RSBs against MODIS Aqua over dark water scenes. Section 2 summarises some relevant features of the sensors, and Sect. 3 presents in detail the calibration methodology applied. Section 4 illustrates the results of the analysis, and Sect. 5 shows the improvement in retrieved AOD resulting from the calibration exercise by applying the SOAR algorithm to VIIRS scenes passing over AERONET sites.

\section{Sensor characteristics}

MODIS (Barnes et al., 1998; Toller et al., 2013) and VIIRS (Cao et al., 2013; Xiong et al., 2016) are both spaceborne broad-swath single-viewing multispectral passive imaging radiometers. VIIRS records data in 22 moderate-resolution bands ( $\mathrm{M}$ bands) across the visible and thermal infrared spectral regions with a nominal pixel size of $750 \mathrm{~m}$ at the centre of the swath. MODIS has a total of 36 bands covering the same spectral region, with nominal pixel sizes of $250 \mathrm{~m}-1 \mathrm{~km}$ at the centre of the swath (dependent on band). Each of these VIIRS $M$ bands has a central wavelength close to one or more MODIS bands. Table 1 shows the band pairs used in this analysis, although MODIS has additional bands, including some others across the visible spectral region of interest here. Note, however, that some of the MODIS bands designed for ocean colour applications saturate at radiances found over land or cloudy scenes; some of the VIIRS RSBs bands are dual-gain and so do not saturate in many of these cases. In this analysis (and also in MODIS routine atmosphere and land data product generation) the relevant so-called MODIS "land bands" (MODIS B1-B7), where a close match is available, are used instead of these ocean colour bands, even when the latter have a closer central wavelength. For simplicity, wavelengths of MODIS/VIIRS band pairs will be referred to using the notation given in the right column of Table 1, although full sensor relative spectral response functions (RSRs) were used for all radiative transfer calculations presented in this work. The RSRs for the bands used are shown in Fig. 1, clearly illustrating that some band pairs are more similar between sensors than others.

VIIRS additionally has five imagery-resolution bands (I bands) with a nominal pixel size of $375 \mathrm{~m}$ and band centres close to some M-band positions, and a Day/Night Band (DNB), which is an enhanced follow-on to the DMSP Operational Line Scanner (OLS; Lee et al., 2006). Neither the I bands nor DNB are used in the present DB or SOAR algorithms, so they will not be discussed further. Likewise, the VIIRS and MODIS TEBs will not be discussed further.

As mentioned previously, stability of MODIS/VIIRS RSBs is monitored and maintained using the SD, SDSM, and lunar rolls (Sun et al., 2007; Wu et al., 2013; Xiong et al., 2016). As a result the RSB absolute calibration for each band is tied to the measured reflectance $\left(\rho_{i}\right)$ rather than radiance, where

$\rho_{i}=\frac{\pi D_{\odot}^{2} \int_{0}^{\infty} L_{\lambda}(\lambda) \Phi_{i}(\lambda) \mathrm{d} \lambda}{\mu_{0} \int_{0}^{\infty} E_{\lambda}(\lambda) \Phi_{i}(\lambda) \mathrm{d} \lambda}$.

In the above $L_{\lambda}$ is the spectral radiance passing into the satellite field of view, $E_{\lambda}$ the downwelling solar spectral ir- 
Table 1. VIIRS moderate-resolution (M) bands and band centres of similar MODIS bands used in this study. The final column indicates the shorthand notation adopted for each respective band pair in this study.

\begin{tabular}{lrrlrr}
\hline $\begin{array}{l}\text { VIIRS band } \\
\text { name }\end{array}$ & $\begin{array}{r}\text { VIIRS band } \\
\text { centre }\end{array}$ & $\begin{array}{r}\text { VIIRS band } \\
\text { width }\end{array}$ & $\begin{array}{l}\text { MODIS band } \\
\text { number }\end{array}$ & $\begin{array}{r}\text { MODIS band } \\
\text { centre }\end{array}$ & $\begin{array}{r}\text { Shorthand } \\
\text { notation }\end{array}$ \\
\hline M01 & $412 \mathrm{~nm}$ & $20 \mathrm{~nm}$ & B8 & $412 \mathrm{~nm}$ & $412 \mathrm{~nm}$ \\
M02 & $445 \mathrm{~nm}$ & $18 \mathrm{~nm}$ & B9 & $442 \mathrm{~nm}$ & $440 \mathrm{~nm}$ \\
M03 & $488 \mathrm{~nm}$ & $20 \mathrm{~nm}$ & B3 & $466 \mathrm{~nm}$ & $470 / 490 \mathrm{~nm}$ \\
M04 & $555 \mathrm{~nm}$ & $20 \mathrm{~nm}$ & B4 & $554 \mathrm{~nm}$ & $550 \mathrm{~nm}$ \\
M05 & $672 \mathrm{~nm}$ & $20 \mathrm{~nm}$ & B1 & $645 \mathrm{~nm}$ & $650 / 670 \mathrm{~nm}$ \\
M06 & $746 \mathrm{~nm}$ & $15 \mathrm{~nm}$ & B15 & $747 \mathrm{~nm}$ & $745 \mathrm{~nm}$ \\
M07 & $865 \mathrm{~nm}$ & $39 \mathrm{~nm}$ & B2 & $867 \mathrm{~nm}$ & $865 \mathrm{~nm}$ \\
M08 & $1240 \mathrm{~nm}$ & $20 \mathrm{~nm}$ & B5 & $1242 \mathrm{~nm}$ & $1240 \mathrm{~nm}$ \\
M09 & $1378 \mathrm{~nm}$ & $15 \mathrm{~nm}$ & B26 & $1370 \mathrm{~nm}$ & $1380 \mathrm{~nm}$ \\
M10 & $1610 \mathrm{~nm}$ & $60 \mathrm{~nm}$ & B6 & $1640 \mathrm{~nm}$ & $1610 \mathrm{~nm}$ \\
M11 & $2250 \mathrm{~nm}$ & $50 \mathrm{~nm}$ & B7 & $2130 \mathrm{~nm}$ & $2130 / 2250 \mathrm{~nm}$ \\
M12 & $3.7 \mu \mathrm{m}$ & $0.18 \mu \mathrm{m}$ & B20 & $3.75 \mu \mathrm{m}$ & - \\
M13 & $4.05 \mu \mathrm{m}$ & $0.155 \mu \mathrm{m}$ & B23 & $4.05 \mu \mathrm{m}$ & - \\
M14 & $8.55 \mu \mathrm{m}$ & $0.3 \mu \mathrm{m}$ & B29 & $8.55 \mu \mathrm{m}$ & - \\
M15 & $10.76 \mu \mathrm{m}$ & $1.0 \mu \mathrm{m}$ & B31 & $11.03 \mu \mathrm{m}$ & - \\
M16 & $12.01 \mu \mathrm{m}$ & $0.95 \mu \mathrm{m}$ & B32 & $12.02 \mu \mathrm{m}$ & - \\
\hline
\end{tabular}
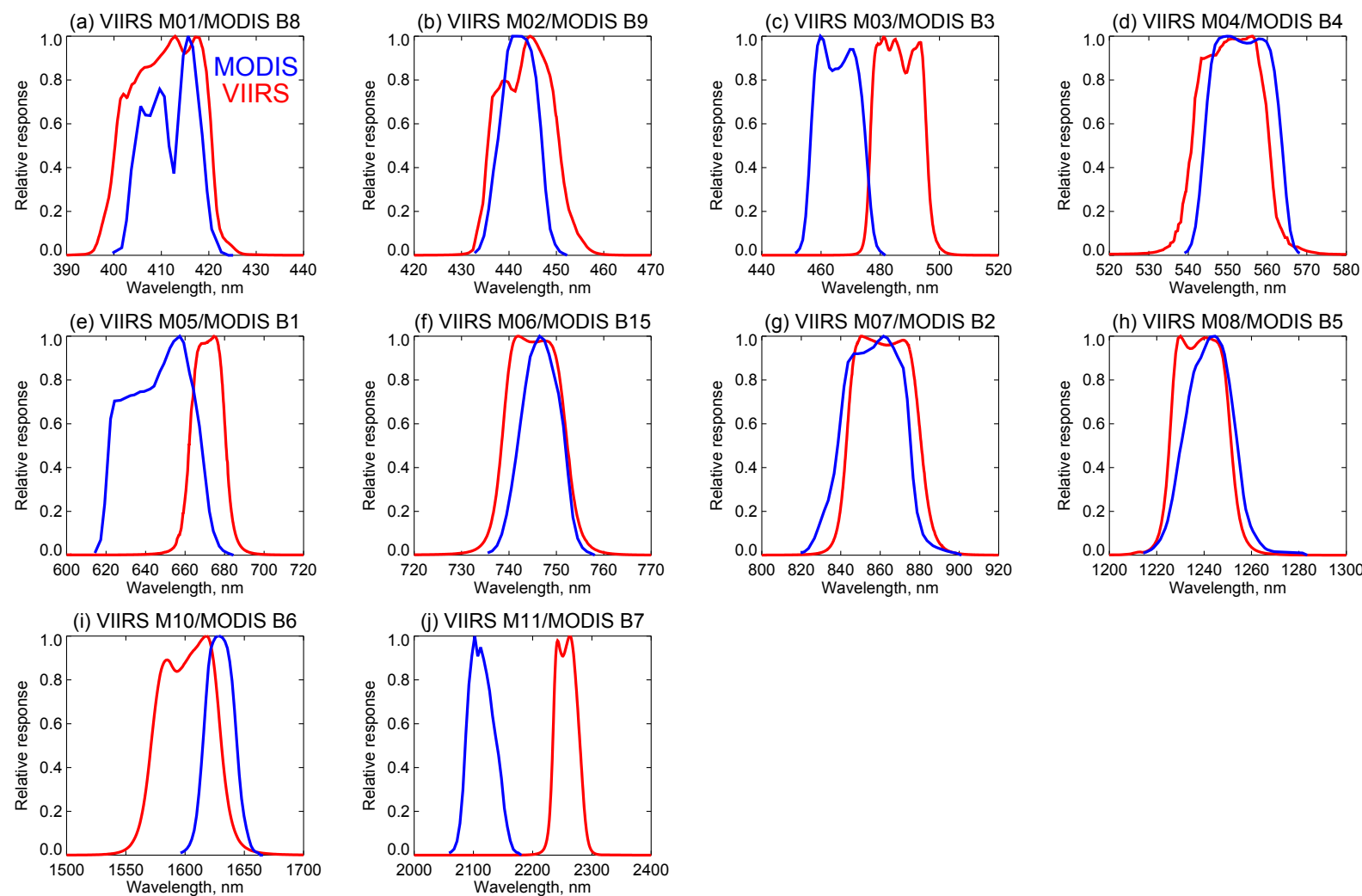
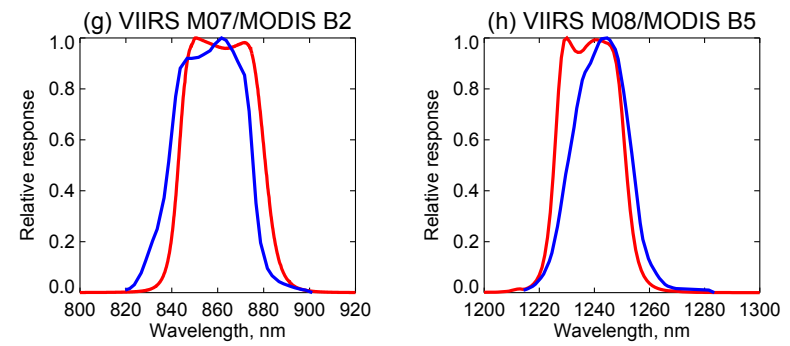

Figure 1. Relative spectral response functions for VIIRS (red) and MODIS (blue) bands used in this study (cf. Table 1).

radiance at TOA, and $\Phi_{i}$ the sensor $\mathrm{RSR}$ for band $i$, all functions of wavelength $\lambda$. The factor $D_{\odot}$ is the Earth-Sun distance in astronomical units (variable throughout the year) and $\mu_{0}$ the cosine of the solar zenith angle, which affect the to- tal solar radiation received. $L_{\lambda}$ and consequently $\rho_{i}$ depend on the surface-atmospheric states and observation geometry, omitted here for simplicity of notation. Equation (1) is often simplified by considering the total radiance $L_{i}$ observed by 
band $i$ :

$L_{i}=\int_{0}^{\infty} L_{\lambda}(\lambda) \Phi_{i}(\lambda) \mathrm{d} \lambda$.

Subscripted $\lambda$ is used to refer to a spectral quantity and subscripted $i$ to the value integrated across sensor band $i$. Analogously, precomputing the spectrally integrated solar irradiance across the band, which then only varies as a function of day of year, gives

$E_{0, i}=\frac{\int_{0}^{\infty} E_{\lambda}(\lambda) \Phi_{i}(\lambda) \mathrm{d} \lambda}{D_{\odot}^{2}}$,

leading to the more common form

$\rho_{i}=\frac{\pi L_{i}}{E_{0, i} \mu_{0}}$.

The radiative transfer codes used in the DB and SOAR algorithms operate in units of Sun-normalised radiance, $L / E_{0}$ (sometimes written $I / F_{0}$ in alternative notation; in both cases, dropping the subscripted $i$ when talking in the general case), to minimise numerical instabilities at large solar zenith angles (i.e. as $1 / \mu_{0}$ tends to infinity). As a result the discussion in the present study also uses units of Sunnormalised radiance, which does not affect the adoption of the results presented herein for other applications. Working in Sun-normalised rather than total radiance also has the advantages of accounting for the effects of the sensors' different RSRs on $E_{0}$ for each band and slightly different solar zenith angles at the times of MODIS and VIIRS observations.

Both sensors suffer from a "bow-tie distortion" which affects the size, shape, and overlap of pixels from nadir to scan edge (Wolfe et al., 2012, 2013). Essentially, as the detector scans across-track pixels become broader and elongated and pixels from consecutive scans overlap, which has consequences for retrieval characteristics as a function of scan angle and can affect statistics of AOD retrievals (Sayer et al., 2015a). VIIRS incorporates several design features to reduce this distortion. The VIIRS native pixel size is actually smaller than the nominal M-band size in the across-track direction. The scan is divided into three regions (in both directions). From nadir out to a scan angle of $31.72^{\circ}$, three pixels are aggregated across-track; from 31.72 to $44.86^{\circ}$ two pixels are aggregated; and from $44.86^{\circ}$ to the edge of scan $\left(56.28^{\circ}\right.$, corresponding to a view zenith angle around $75^{\circ}$ ) no aggregation is performed. This limits across-track distortion at the end of each aggregation zone to a factor of 2 compared to a factor of about 6 without this oversampling and aggregation. Additionally, at the outer two aggregation zones, two and four pixels, respectively, are deleted from the edge of scan (so-called "bow-tie deletion") to minimise the degree to which consecutive scans overlap (although not all overlap is removed by this).
S-NPP and Aqua are both in Sun-synchronous orbits with daytime equatorial local solar crossing times at the centre of swath around 13:30 UTC. However, orbit altitudes (averages of $705 \mathrm{~km}$ for Aqua and $839 \mathrm{~km}$ for S-NPP) and inclination are different, which mean that the sensors are not always observing the same location (near-simultaneous observations within 10 min occur roughly every other day, covering only a segment of the world each time). Both satellites' orbital repeat cycles last 16 days. The MODIS swath width is approximately $2330 \mathrm{~km}$, providing near-global daily daytime coverage (there are gaps between consecutive orbits at low latitudes) while VIIRS has a sufficiently broad swath $(3040 \mathrm{~km})$ that consecutive orbits overlap, even at the Equator. Both sensors have some degree of overlap between consecutive orbits at mid- and high latitudes.

\section{Cross-calibration methodology}

This analysis seeks to calibrate L1 reflectance in VIIRS bands M01-M11 (spectral range 412-2250 nm) against the corresponding MODIS Aqua bands shown in Table 1. Band M09 is not considered; this band (for both MODIS and VIIRS) is located in a spectral region of strong water vapour absorption and so is typically used in threshold tests to detect high cloud tops (cirrus or deep convective clouds) rather than in geophysical retrieval algorithms (e.g. Frey et al., 2008), and the quality of its absolute calibration in MODIS is unclear. All corrections presented herein represent scaling factors which should be applied for NASA VIIRS L1 data to make it radiometrically consistent with NASA MODIS Collection $6 \mathrm{~L} 1$ data and account for the fact that the sensors have different spectral response functions (i.e. correcting for the unexpected portion of any observed discrepancy between the two). The steps of this exercise are listed here and outlined in detail in the following subsections:

1. selection of appropriate MODIS/VIIRS pixels to consider;

2. correction for the effects of absorption by trace gases in the atmosphere;

3. forward radiative transfer modelling to predict the TOA reflectance which should be observed by VIIRS, given that observed by MODIS (i.e. calculating the expected level of difference);

4. aggregation of results to a monthly timescale and derivation of cross-calibration scaling coefficients (i.e. comparing the observed and expected level of difference and making a correction to bring these in line).

\subsection{Data description and selection of appropriate pixels}

The NASA VIIRS data processing is facilitated by Science Investigator-led Processing Systems (SIPS) for each science 
discipline. In support of this, the VIIRS Atmospheres SIPS at the University of Wisconsin (http://sips.ssec.wisc.edu) have created "matchfiles" of collocated VIIRS and MODIS Aqua observations to more easily compare the two sensors. These matchfiles form the basis of the present analysis, and have been created from the MCST MODIS Aqua Collection 6 data (at $1 \mathrm{~km}$ nominal pixel size, the MYD021KM product) and VCST VIIRS Version 2.0 data (the VL1BM product). These are the current versions of the L1 data for both sensors used in routine processing of MODIS, which will be used for the first processing of the VIIRS Deep Blue/SOAR L2 data products (as well as other NASA VIIRS data products produced by the Atmospheres and Land SIPS). The time period considered is from March 2012 (several months after the S-NPP launch, at which point the VIIRS M-band RSB/TEB data were considered ready for use) to 26 July 2016 inclusive. On 27 July 2016 MCST made a change to MODIS calibration in some bands in forward-processing mode, which could introduce a discontinuity, and so the analysis was stopped at this time (A. Angal, personal communication, 2017).

The matchfiles contain L1 RSB/TEB data, geolocation, and land-sea mask information for MODIS and VIIRS, with VIIRS pixels mapped into MODIS pixels (due to a combination of native spatial resolution and bow-tie distortions, VIIRS pixels are typically smaller than MODIS ones). Because of this, the matchfiles contain the mean and standard deviation of VIIRS RSB reflectance/TEB radiance within the area of each MODIS pixel, as well as that corresponding to the nearest VIIRS M-band pixel to the centre of each MODIS pixel. The files also contain the MODIS Collection 6 cloud mask for each MODIS pixel (the MYD35 data product; an updated version of that described by Frey et al., 2008).

Two additional ancillary data sets were used in the analysis. The first is the Goddard Earth Observing System Model Version 5 (GEOS-5) Forward Processing for Instrument Teams (FPIT), available from http://gmao.gsfc.nasa. gov/GEOS, at $0.5^{\circ}$ latitude, $0.625^{\circ}$ longitude, and 3-hour temporal resolution. Surface winds and $\mathrm{O}_{3}$ and $\mathrm{H}_{2} \mathrm{O}$ total column abundances were extracted and interpolated linearly to each pixel in the matchfiles. The second is climatologies of oceanic chlorophyll- $a$ concentration $(\mathrm{Chl})$ derived from the SeaWiFS record, available from http://oceancolor.gsfc.nasa. gov. These are provided at a native spatial resolution of $9 \mathrm{~km}$ and one data set for each of the 12 months of the year; to fill gaps, for the present analysis these were degraded to $0.25^{\circ}$ spatial resolution by taking a median average and remaining gaps were filled using the nearest available month of the year in time (for a gap in March, data from February and April are used; if also missing then data from January and May, etc). The resulting gap-filled climatology was also interpolated linearly (in units of $\log _{10} \mathrm{Chl}$ ) to each pixel in the matchfiles.

Matched MODIS/VIIRS pixels were then selected for further analysis if they passed all of the following criteria:
- The difference in observation time was under $10 \mathrm{~min}$, to minimise changes in the surface-atmospheric state between observations.

- The view zenith angle and scattering angle differences were both smaller than $3^{\circ}$, to minimise uncertainties related to the geometric dependence of the scenes viewed (e.g. surface reflectance, atmospheric absorption, and scattering phase matrices). Note that the observation time threshold mentioned above also effectively acts as a threshold on solar zenith angle difference.

- The MODIS land mask classification was "deep inland water", "moderate or continental ocean", or "deep ocean", and the climatological $\mathrm{Chl}<1 \mathrm{mgm}^{-3}$, to remove cases where the ocean surface reflectance model used (see later) may be less appropriate.

- The MODIS cloud mask classification was "confidently clear", and the pixel was at least $5 \mathrm{~km}$ away from any pixel classed as "confidently cloudy" or "uncertain". This distance threshold removes approximately $80 \%$ of "confidently clear" pixels, although it decreases the likelihood of errors resulting from cloud movement between the MODIS/VIIRS overpass times or classification errors (i.e. cloud contamination) and $3 \mathrm{D}$ radiative transfer effects.

- The relative standard deviation of VIIRS $670 \mathrm{~nm}$ reflectance within MODIS pixels was $<25 \%$, to remove residual inhomogeneous scenes.

- Solar zenith angles were smaller than $70^{\circ}$, to minimise shadow length and parallax effects and ensure a strong daytime RSB signal.

- The latitude was equatorward of $60^{\circ}$, as ship-based observations suggest that background oceanic aerosol optical characteristics at polar latitudes can differ from those at lower latitudes (Smirnov et al., 2011).

- Sun glint contribution to Sun-normalised radiance (from GEOS-5 winds and the model of Cox and Munk, 1954a, b) was $<0.01$ for both sensors, as over-ocean radiative transfer modelling is subject to higher uncertainties in glint hotspots.

- Total column $\mathrm{H}_{2} \mathrm{O}$ was less than $3 \mathrm{~cm}$, to decrease uncertainties related to trace gas absorption (because this can have a large absorption in NIR and SWIR bands and exhibits fairly large spatiotemporal variability). Note that, although the bulk of matched pixels occur in the mid- and high latitudes, this constraint removes most of the potential matchups in tropical regions (since these often have water vapour amounts in excess of this threshold). 
Figure 2 shows an example of the results of applying the above filters to matchfiles created from a pair of MODIS/VIIRS granules, separated by $1 \mathrm{~min}$ in acquisition time.

\subsection{Correction for trace gas absorption}

The next step is to correct the TOA MODIS/VIIRS RSB reflectances for the effects of absorbing trace gases. Note that the corrections described here are also applied in NASA VIIRS DB/SOAR processing. An assumption commonly made in atmospheric and/or surface retrieval algorithm processing is that the molecular absorption can be decoupled from other contributions to the TOA signal, and so corrected for by applying a "brightening" factor to the observed TOA reflectances. In the visible spectral region, this is justified because the optical depths of the absorbing species are fairly small, and (particularly in the case of $\mathrm{O}_{3}$ ) the bulk of the absorption is located higher in the atmosphere than the main other contributors to the signal (Rayleigh scattering, aerosols, and surface reflectance), so corrections for this absorption can be developed with high accuracy (Gueymard, 1995). The computational advantage of performing such a correction is that it vastly decreases the dimensionality of radiative transfer lookup tables (LUTs) used in the retrieval process, since individual gas species and their variable vertical profiles do not need to be built in to them.

This analysis uses the same approach taken in operational MODIS aerosol processing (Appendix A of Levy et al., 2013), with the additional step that, following Tanré et al. (1992), the effective column $\mathrm{H}_{2} \mathrm{O}$ amount is taken as half the total column $\mathrm{H}_{2} \mathrm{O}$ to better account for the atmospheric vertical structure. In brief, gas absorption is calculated by the Line-By-Line Radiative Transfer Model (LBLRTM; Clough et al., 2005), which includes the High Resolution Transmission (HITRAN) gas absorption data base (http://hitran.org), used in combination with the MODIS and VIIRS RSRs to calculate the absorption by atmospheric trace gases as a function of their amount and vertical profile shape. The effective air mass factors for absorption, which includes the effects of the Earth's curvature and typical gas profiles, are obtained from Gueymard (1995). GEOS-5 data (discussed previously) are used to obtain $\mathrm{O}_{3}$ and $\mathrm{H}_{2} \mathrm{O}$ column amounts, while climatological abundances are used for the other species considered $\left(\mathrm{CO}, \mathrm{CO}_{2}, \mathrm{~N}_{2} \mathrm{O}, \mathrm{NO}_{2}, \mathrm{CH}_{4}, \mathrm{O}_{2}, \mathrm{SO}_{2}\right)$, since their contributions to the total absorption are weak and/or their spatiotemporal variability comparatively low. Note that $\mathrm{NO}_{2}$ variability, and consequently absorption, can be significant (Ahmad et al., 2007) for sensor bands in the blue spectral region $(412 \mathrm{~nm}$, and to a lesser extent $440-490 \mathrm{~nm})$. However, the exclusion of pixels close to land masses (Sect. 3.1) means that this is not an issue for the data considered here, since background oceanic levels are low due to a lack of strong sources, and the short lifetime of $\mathrm{NO}_{2}$ means that long-range transport is fairly small.
The gas absorption corrections are calculated for and applied to each pixel and band. After applying these corrections, the MODIS/VIIRS RSB L1 data are effectively that which would be seen by the sensors in the absence of these trace gases in the atmosphere, removing one cause of differences in TOA reflectance between the two instruments. This step is important because, despite the similarity of band central wavelengths (Table 1), RSR shapes can be sufficiently different (Fig. 1) that differences in the level of gas absorption for nominally similar bands can be non-negligible in some cases. Thus, not taking gas absorption into account could lead to biases in the cross-calibration exercise. This is illustrated in Fig. 3: while some bands, such as MODIS B4/VIIRS M04 (both centred near $550 \mathrm{~nm}$ ), are very similar and gas corrections are tightly correlated and close to $1: 1$, others show more difference in magnitude and/or spread, illustrating the importance of accounting for trace gas absorption accurately when comparing L1 data from the two sensors.

\subsection{Forward radiative transfer modelling of predicted VIIRS reflectance}

The next step is to determine, given the observed MODIS TOA reflectance, what reflectance VIIRS should see for each pixel. Because of the differences between sensor RSRs (Fig. 1), and the slight differences in observation geometry between the two sensors for a given pixel, this requires a radiative transfer forward model, and the results of the analysis will be sensitive to the assumptions made in that forward model. This analysis uses the VLIDORT radiative transfer model (Spurr, 2006), which is the same as is used in the NASA VIIRS SOAR data set and allows for a detailed description of aerosol properties and surface bidirectional reflectance distribution function (BRDF), a pseudospherical atmosphere, and a vector treatment of the atmospheric radiation field, which is important for accurate radiative transfer at short visible wavelengths (e.g. Levy et al., 2004). It is also able to account for the full RSRs of the sensors when performing calculations. This radiative transfer model has some advancements over those used previously by DB/SOAR; it has been benchmarked against standard results with good performance (Spurr, 2006), and versions have also been used for other aerosol remote sensing applications (e.g. Jethva et al., 2013; Wang et al., 2014; Sayer et al., 2016).

\subsubsection{Aerosol optical model}

As the comparison is restricted to open-ocean scenes, it is a reasonable assumption that most of the AOD is contributed by "clean" (i.e. little continental influence) maritime aerosols (e.g. O'Dowd and de Leeuw, 2007). For this reason, the "pure marine" aerosol optical model of Sayer et al. $(2012 b)$ is used. This model was based on AERONET inversions (Dubovik and King, 2000) from a variety of sites, 


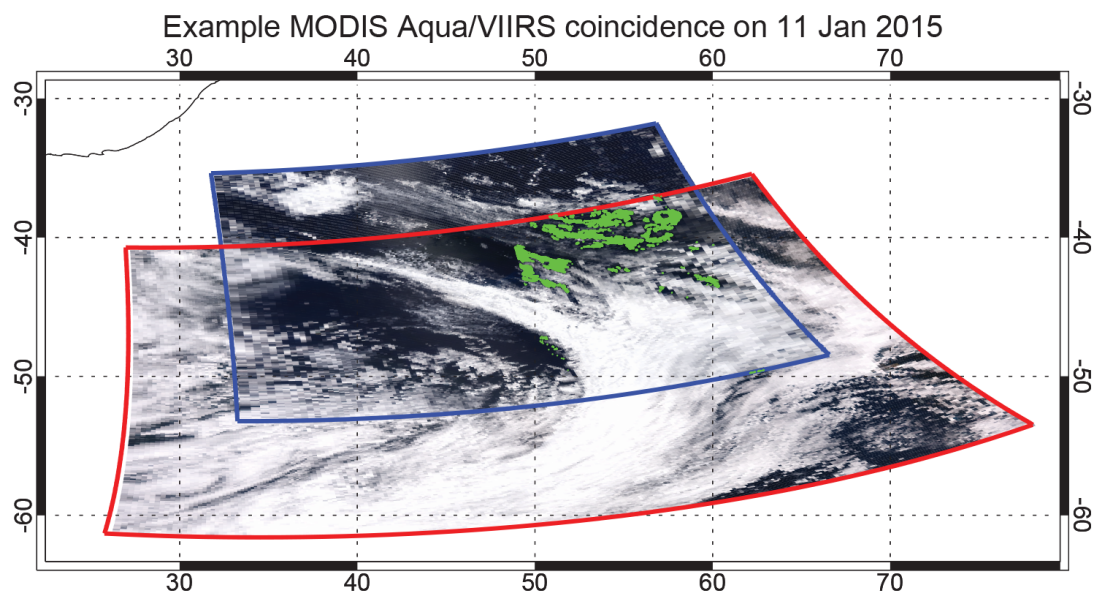

Figure 2. Example MODIS/VIIRS match up for two near-coincident granules (beginning 1 min apart). The S-NPP VIIRS granule is outlined in red and MODIS Aqua in blue. Suitable matched pixels are shown in green.

(a) $412 \mathrm{~nm}$

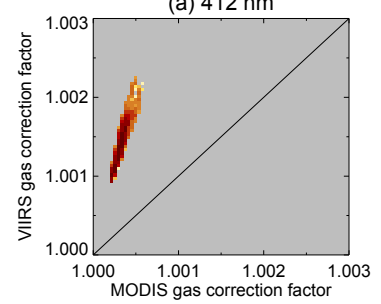

(e) $650 / 670 \mathrm{~nm}$

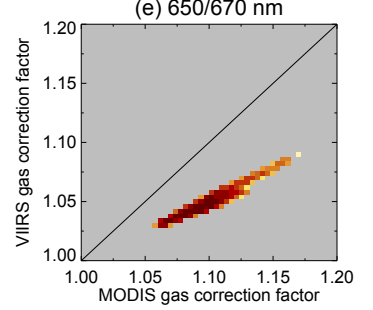

(i) $1610 / 1640 \mathrm{~nm}$

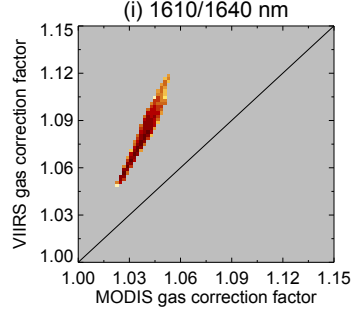

(b) $440 \mathrm{~nm}$

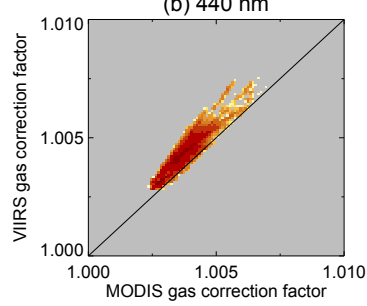

(f) $745 \mathrm{~nm}$

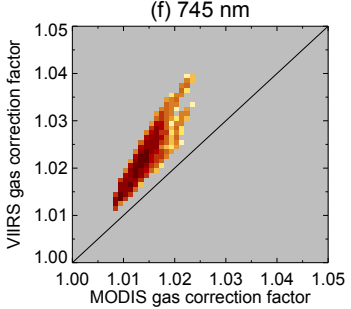

(j) $2130 / 2250 \mathrm{~nm}$

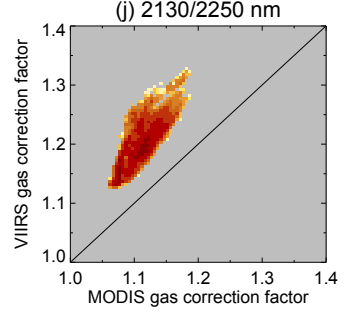

(c) $470 / 490 \mathrm{~nm}$

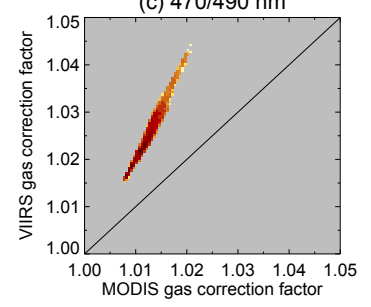

(g) $865 \mathrm{~nm}$
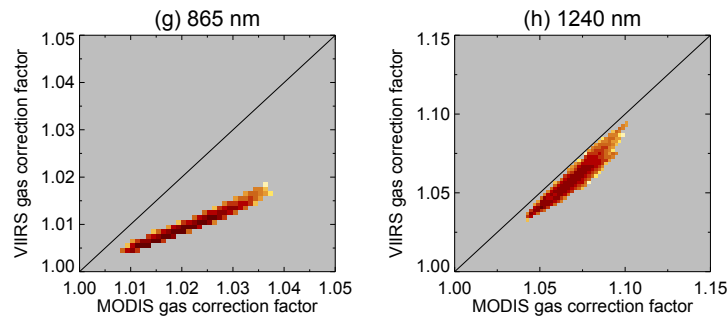

(d) $550 \mathrm{~nm}$

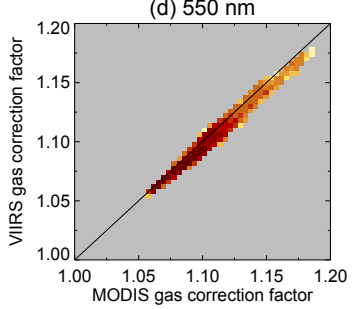

(h) $1240 \mathrm{~nm}$

Frequency

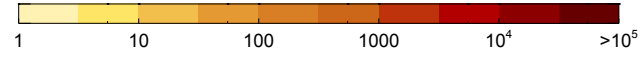

Figure 3. MODIS/VIIRS spectral trace gas absorption corrections for suitable matched pixels in January 2016.

was applied previously in SeaWiFS SOAR processing (Sayer et al., 2012a), and is also applied in VIIRS SOAR data processing. Real and imaginary aerosol refractive indices were taken from Hess et al. (1998), as there are few measurements of aerosol optical properties across the whole VIIRS spectral range. Specifically, the fine mode uses the "watersoluble" component refractive indices and the coarse mode the "coarse-mode sea salt" component, both for aerosols at $70 \%$ relative humidity. In the radiative transfer simulations the aerosol is assumed to occupy a homogeneous vertical layer from the surface to $1 \mathrm{~km}$ altitude; as the aerosol is close to non-absorbing, and the data are further filtered for lowAOD conditions (discussed further later), the vertical structure has little influence on the modelled TOA signal.

The standard assumption made in the analysis is that the aerosol fine mode fraction (FMF) of optical depth at $550 \mathrm{~nm}$ is 0.4 , which is a typical value determined from observations in a variety of global oceans (Smirnov et al., 2011). However, to assess the uncertainty resulting from this assumption 
(discussed later), radiative transfer simulations are also performed for $\mathrm{FMF}=0.2$ and $\mathrm{FMF}=0.6$.

\subsubsection{Surface reflectance model}

The ocean surface BRDF is an updated version of the treatment used by Sayer et al. (2012a) for SeaWiFS, and the same model discussed herein is also applied for SOAR VIIRS processing. The BRDF model draws on the widely used method of Koepke (1984) and includes contributions from oceanic whitecaps, Sun glint, and scattering from within the water ("underlight", using the basic formalism of Austin, 1974). Both the whitecap and underlight terms have been updated since the SeaWiFS application. The wind speed dependence of the whitecap formulation has been updated using the formulation of Callaghan et al. (2008), which tends to slightly decrease the whitecap contribution to the BRDF at most wind speeds, since Callaghan et al. (2008) and other studies suggest that the older formulation used previously (Monahan and Muircheartaigh, 1980) may overestimate the whitecap fraction.

Underlight is calculated using an empirical relationship based on Chl to estimate absorption and scattering from pigments and co-varying materials. This relationship was developed for so-called "Case 1" (largely open-ocean) waters (Morel and Prieur, 1977). Within the underlight component of the reflectance model, several updates have been made to the assumed water absorption/scattering properties (previously taken from Smith and Baker, 1981). Lee et al. (2015) found that prior estimates of the absorption coefficient of water at visible and ultraviolet wavelengths were too high, and so the Lee et al. (2015) coefficients have been adopted instead over their available spectral range $(300-550 \mathrm{~nm})$. The results of Pope and Fry (1997) are used for 550-725 nm, which results in smooth continuity with the results of Lee et al. (2015), and those of Hale and Querry (1973) are used for longer wavelengths (although above $700 \mathrm{~nm}$ water absorption is so strong that ocean reflectance depends negligibly on chosen data source). The water scattering coefficient was also updated according to Zhang et al. (2009) and chlorophyll absorption spectrum updated according to Lee et al. (1998) and Vasilkov et al. (2005). At the same time, the spectral range of the parametrisation has been extended to $300-900 \mathrm{~nm}$ (from the prior $400-700 \mathrm{~nm}$ ). Directional aspects of the underlight contribution (so-called $f / Q$ ratio) have also been updated according to Morel et al. (2002).

The combined effect of these coefficient updates, relative to prior implementations of the same basic model (Sayer et al., 2010, 2012a) is an increase of up to a few tens of percent in the underlight contribution to ocean reflectance for the blue and green spectral region $(550 \mathrm{~nm}$ and shorter wavelengths), which translates to a few percent in TOA reflectance.
Table 2. Summary table showing the node points used in the MODIS/VIIRS intercalibration LUT.

\begin{tabular}{ll}
\hline Parameter & Nodes \\
\hline Solar zenith angle & $4^{\circ}$ spacing from 0 to $84^{\circ}$ \\
View zenith angle & $4^{\circ}$ spacing from 0 to $76^{\circ}$ \\
Relative azimuth angle & $9^{\circ}$ spacing from 0 to $180^{\circ}$ \\
Near-surface wind speed & $1,3,6,9,12,15 \mathrm{~ms}^{-1}$ \\
Chl & $0.01,0.032,0.1,0.32,1 \mathrm{mgm}^{-3}$ \\
AOD at $550 \mathrm{~nm}$ & $0,0.04,0.08,0.12,0.16,0.2,0.24$ \\
FMF at $550 \mathrm{~nm}$ & $0.2,0.4,0.6$ \\
\hline
\end{tabular}

\subsubsection{LUT creation and application}

To use MODIS observations as a predictor for VIIRS, VLIDORT has been used to construct a pair of LUTs of MODIS and VIIRS reflectance for a variety of surface and atmospheric conditions for each band. The node points are shown in Table 2, and their spacing has been chosen such that the linear interpolation error between node points is less than $1 \%$ (relative) error in Sun-normalised radiance, with the average bias across conditions negligible.

The LUT is used by looping over each matched MODIS/VIIRS pixel pair and band, using the measured MODIS TOA Sun-normalised radiance to estimate the AOD at the reference wavelength of $550 \mathrm{~nm}$ (based on the ancillary MODIS geometric information, wind speed, Chl climatology, and assumed aerosol optical model). This derived AOD is then used (together with the VIIRS geometric information) to predict the Sun-normalised radiance VIIRS would be expected to see if its absolute calibration were equal to that of MODIS. For each pixel, this process is repeated for each band independently and for each of the three aerosol FMF assumptions $(0.2,0.4,0.6)$. This dynamic AOD estimation, rather than assuming e.g. a single AOD across all scenes, ensures that the spectral MODIS TOA Sun-normalised radiance is matched exactly for each pixel and band, which decreases the uncertainties involved in cross-calibrating the two sensors. One important point to note is that, as the calibration of VIIRS is being tied to that of MODIS, what is most important here is not so much the absolute accuracy of the radiative transfer modelling or AOD estimation step but rather the accuracy of the spectral/directional extrapolation between MODIS and VIIRS wavelengths and geometries.

A further filtering step takes place at this stage. Pixels are only retained when, for each band and for each of the FMF assumptions, an exact match to the MODIS reflectance is found with a $550 \mathrm{~nm}$ AOD from 0 to 0.2. This removes residual cases where the forward model may be inappropriate, e.g. contamination by clouds/cloud shadows or continental (e.g. smoke, dust) aerosols where the aerosol optical model assumption may be significantly in error or cases where the ancillary data (Chl, wind speeds, trace gas abundances) are significantly in error. This decreases the available data volume 


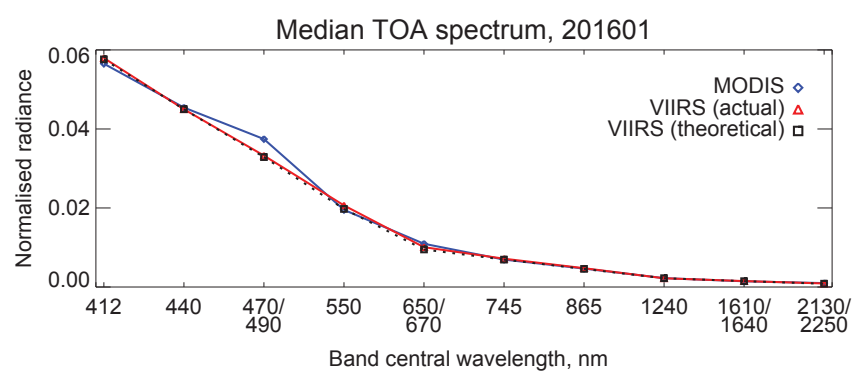

Figure 4. Median spectral observed TOA Sun-normalised radiance for MODIS (blue) and VIIRS (red) bands and (black dashed) modelled expected VIIRS signal, after the AOD estimation and filtering steps described in Sect. 3.3.3. Data are from January 2016.

but helps to ensure that the remaining pixels correspond to clean open-ocean cases where the transfer between MODIS and VIIRS spectral and directional characteristics has been achieved with high fidelity and retains identical spatiotemporal sampling for all bands. Note that the standard deviation of $550 \mathrm{~nm}$ AOD estimated independently using this aerosol optical model from each band is 0.01 or less between bands in most cases, indicating that any spectral biases in the radiative transfer model are small.

At the end of this stage, each suitable pixel and band have associated MODIS and VIIRS TOA RSB observations, plus an estimate of the TOA signal which VIIRS would be expected to see, under the assumption that MODIS Aqua's calibration is correct. An example of the results, composited from the points obtained in January 2016, is shown in Fig. 4. This shows the expected spectral dependence of the TOA signal over open ocean: a darkening as wavelength increases, because Rayleigh scattering, oceanic surface reflectance, and aerosol scattering all decline at longer wavelengths. MODIS at $470 \mathrm{~nm}$ is notably brighter than VIIRS at the VIIRS band near $490 \mathrm{~nm}$, and to a lesser extent for the $650 / 670 \mathrm{~nm}$ pair, for these reasons. The theoretical predicted VIIRS TOA signal is much closer to the observed VIIRS than observed MODIS for these bands, illustrating again the importance of accounting for the differences in sensor RSRs rather than just comparing the TOA signals directly (i.e. differences resulting from sensor spectral characteristics may be larger than those resulting from sensor calibration errors).

\subsection{Aggregation to monthly timescales and calculation of cross-calibration correction}

The final step in the analysis is to aggregate the pixel-level results to a monthly timescale and use these to derive crosscalibration coefficients. The rationale for a monthly time step is that results derived from observations on a single day are likely to have correlated errors (in terms of forward model and ancillary data), as they are drawn from a limited spatial and temporal snapshot of the world. In contrast, averaging to a month should provide sufficient sampling that errors can be averaged out to a large extent. Aggregation also minimises the influence of remaining outliers. At the same time, monthly timescales remain sufficiently short that any longerterm behaviour, such as seasonality or drifts in the relative calibration, can be examined.

For each month and band, the remaining pixels are sorted by the theoretical VIIRS $L / E_{0}$ (i.e. the signal VIIRS is expected to report, given the MODIS observations and the spectral/directional differences between the sensors' observations, as modelled through VLIDORT) and divided into 50 equally populated bins. For each bin, the median theoretical and actual VIIRS $L / E_{0}$ are recorded. Binning data, and use of medians rather than means, decreases the sensitivity to outliers caused by real scene changes, cloud contamination, or radiative transfer errors. An example of this process for January 2016 is shown in Fig. 5.

The cross-calibration gain correction (to make VIIRS radiatively consistent with MODIS Aqua for a given Earth scene) derived for this month of data is simply the mean ratio between these binned values, and VIIRS L1 reflectances can be "corrected" to be unbiased with respect to MODIS Aqua by multiplying the TOA signal (whether in reflectance or $L / E_{0}$ units) for the band in question by this number. This correction represents the scaling factor to apply to the VIIRS L1 reflectance data to make it radiatively consistent with MODIS Aqua, accounting for the expected differences due to the differences in RSRs. It is important to emphasise again that this is a correction to the VIIRS reflectances, not VIIRSderived AOD, that is not tied to the SOAR AOD retrieval algorithm, and this correction accounts for the RSR differences but does not attempt to act as a "shift" of the VIIRS bands (e.g. the VIIRS band M03 centred near $490 \mathrm{~nm}$ should still be treated as such with its full spectral response function; the correction is not trying to shift it to be a pseudo-MODIS band 3 centred near $470 \mathrm{~nm}$ ).

This ratio approach is inherently making the assumption that the calibration correction is a simple gain scaling factor, that it is linear, and that there is no offset between the two for the darkest scenes; this is generally expected to be the case on physical and engineering grounds, and as a result the assumption is common in such calibration exercises (Franz et al., 2007; Cao et al., 2013, 2014; Uprety et al., 2013, 2014; Lyapustin et al., 2014; Uprety and Cao, 2015; Wang and Cao, 2016). If linear least-squares regression is performed on the binned data (not shown) rather than simply taking the mean of the ratios between the bin-median values, then the effective gain coefficients are similar and offsets are close to zero, although there is a little more month-to-month variation since two free parameters are being determined (offset and gradient) and a deviation in one of these parameters is countered by a deviation of opposite direction in the other. Thus, the numerical effects on corrected TOA reflectance, or $L / E_{0}$, is negligible whether the bin-ratio or linear regression technique is used. 
(a) $412 \mathrm{~nm}(\mathrm{M} 01)$

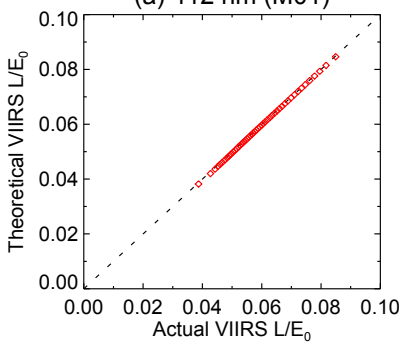

(e) $670 \mathrm{~nm}(\mathrm{M05})$

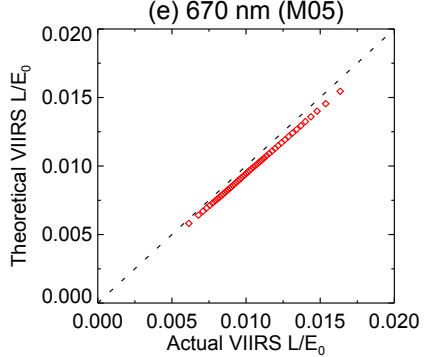

(i) $1610 \mathrm{~nm}(\mathrm{M} 10)$

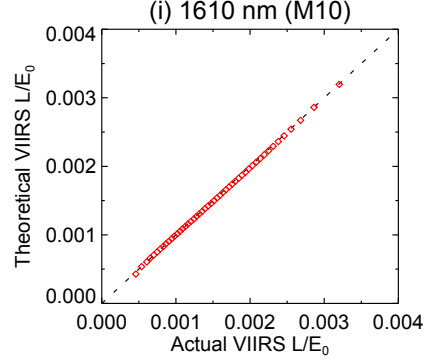

(b) $440 \mathrm{~nm}$ (M02)
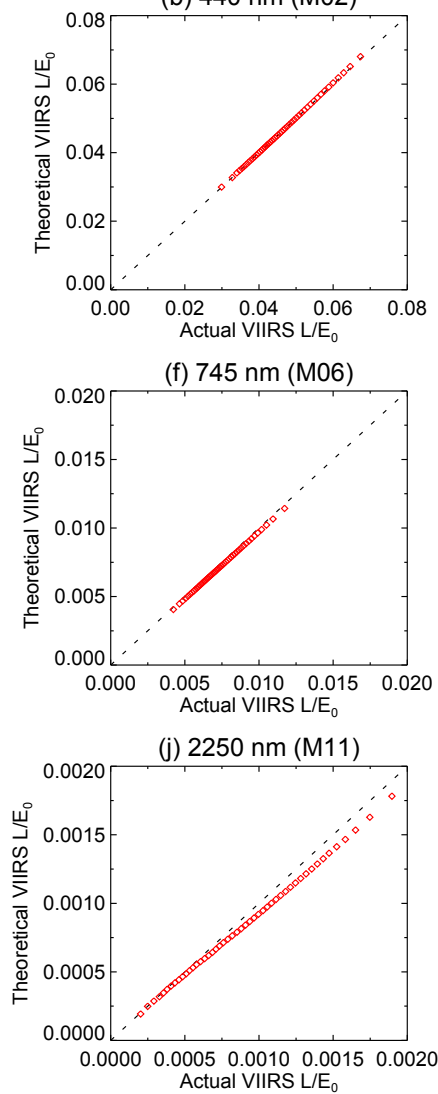

(c) $490 \mathrm{~nm}(\mathrm{M} 03)$

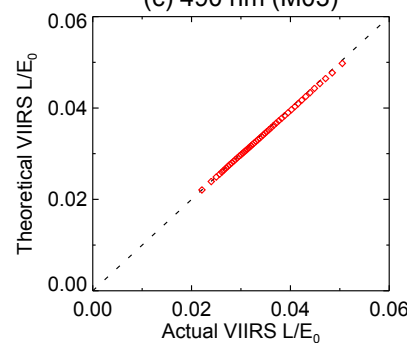

(g) $865 \mathrm{~nm}(\mathrm{M07})$

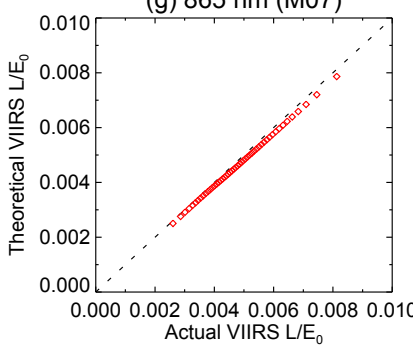

Actual VIIRS L/E (d) $550 \mathrm{~nm}(\mathrm{M} 04)$

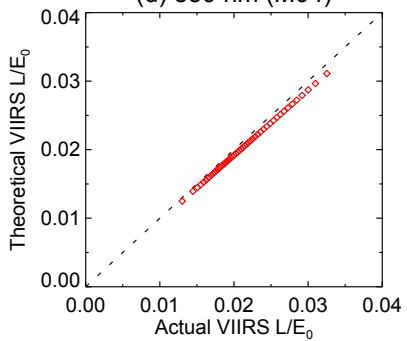

(h) $1240 \mathrm{~nm}$ (M08)

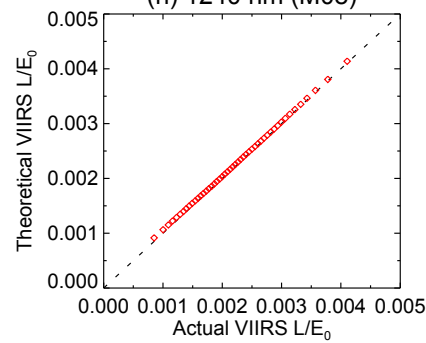

Figure 5. Bin-median observed and theoretical predicted VIIRS TOA Sun-normalised radiance $\left(L / E_{0}\right)$ for suitable matched pixels in January 2016. The dashed line indicates a $1: 1$ relationship.

Further, linear coefficients of determination between the binned theoretical and actual VIIRS signals are close to unity $\left(R^{2}>0.99\right)$, indicating that the assumption of linearity is justified in this case. Note that this does not preclude detector non-linearities across the whole range of VIIRS brightnesses because the present analysis is restricted to scenes over ocean, which are (particularly for the SWIR bands) fairly dark.

\section{Derived gain corrections, time series, and uncertainty}

Performing the steps detailed in Sect. 3 results in data distributed regionally and seasonally as shown in Fig. 6. Some regions are sampled frequently and others never, due to the intersection of the two satellites' 16-day repeat cycles. Seasonal variations are caused predominantly by variations in cloud cover and land (more land in the Northern Hemisphere) and secondarily by changes in solar angle (which affects the Sun glint location, latitudes of daylight, as well as scattering angle differences).

The distribution of these points in time is shown in Fig. 7. As well as seasonal variability (caused by the aforementioned factors), the available data volume is larger from 2014 onwards than in 2012 and 2013. This can be explained by the satellites' orbital times. Figure 8 shows the equatorial local solar crossing times of the ascending (i.e. daytime) nodes for both sensors. While both are often quoted as a nominal 13:30 UTC crossing time, neither orbits at exactly this time. Aqua's orbit crosses around 13:35 UTC, with small seasonal variability, and is very tightly controlled as it flies as part of the A-Train constellation. S-NPP was initially closer to 13:25 UTC and this has gradually changed through the mission as a result of spacecraft orbital adjustments, with the two platforms' crossing times within 5 min from mid-2014 to mid-2015. As a result, the $10 \mathrm{~min}$ time difference threshold imposed on the analysis (Sect. 3.1), imposed to minimise the influence of changes in the scene viewed between the two sensors' overpasses, is more restrictive in 2012 and 2013 (aside from the influence of seasonality, fewer matchups during this time than later in the mission). Note that these changes in crossing time remain within the missions' tolerance requirements. It is also worth noting that these changes in Equator crossing time do not strongly influence the geographic distribution of matched pixels.

Compositing the monthly results (e.g. Fig. 5) gives the time series shown in Fig. 9. The three SWIR bands show 
(a) Matchup locations, DJF

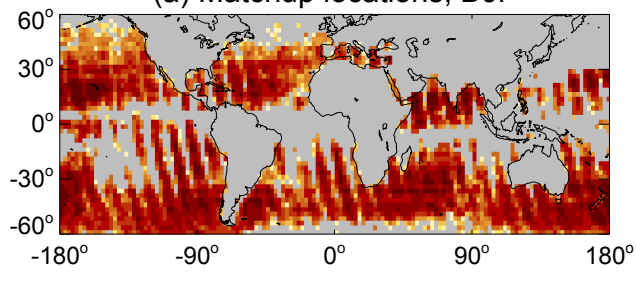

(c) Matchup locations, JJA

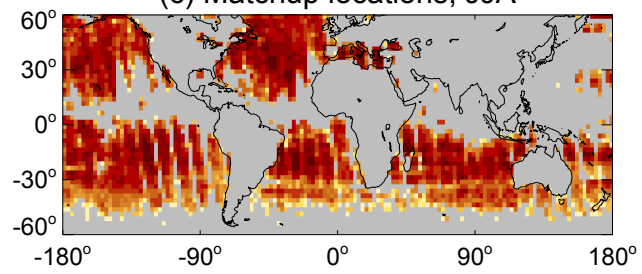

(b) Matchup locations, MAM

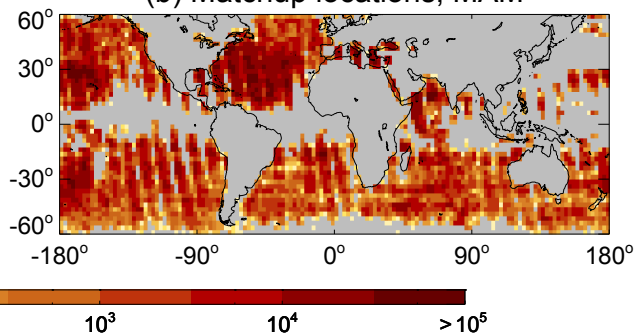

(d) Matchup locations, SON

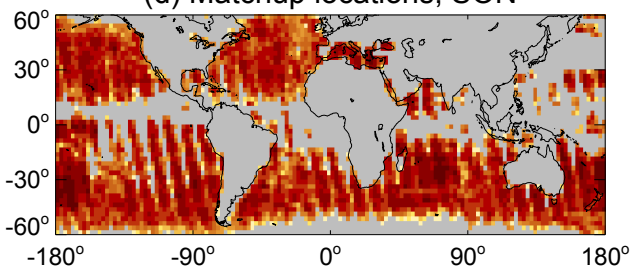

Figure 6. Seasonal spatial distribution of matched MODIS/VIIRS pixels used for the vicarious calibration exercise, aggregated to a $2.5^{\circ}$ horizontal grid size.

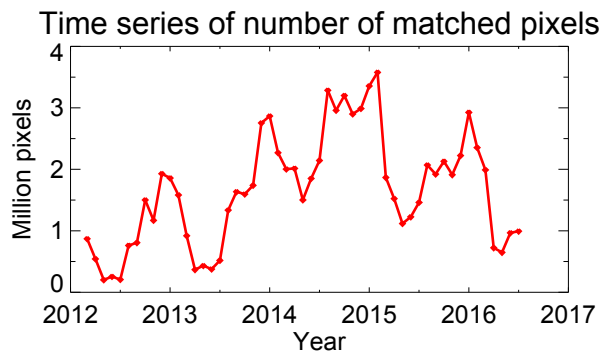

Figure 7. Time series of the number of matched MODIS/VIIRS pixels per month after all quality checks and filtering.

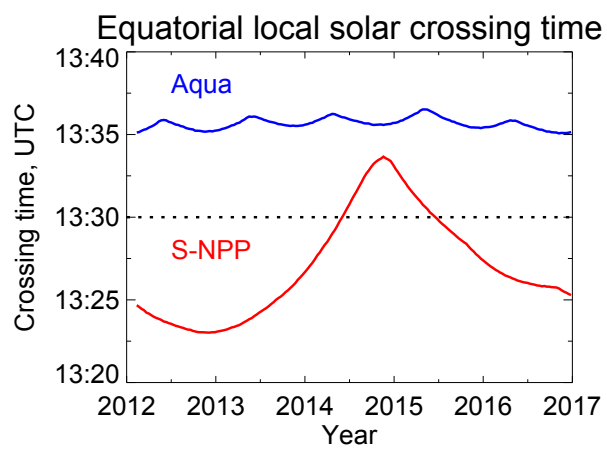

Figure 8. Variation of S-NPP (red) and Aqua (blue) satellite equatorial local solar crossing times for the ascending (daytime) orbital nodes. The dashed line indicates the nominal 13:30 UTC crossing time often used as shorthand when discussing these platforms.

more noise than the others, which is expected since both ocean and atmosphere are quite dark at these wavelengths, and the resulting ratios of small numbers are inherently less stable than ratios for brighter bands. Several bands show seasonal oscillation and it is unclear at present to what extent this is caused by both sensors' individual radiometric stability and to what extent this may be related to seasonal changes in geographical sampling (as it is possible that assumptions made in the analysis may be more or less appropriate in different regions, leading to residual geographic error). Nevertheless, these seasonal oscillations, where present, tend to be small (amplitude $<0.01$, i.e. $<1 \%$ ).

In addition, several bands show an apparent trending in the cross-calibration scaling factor over the five-year period. For band M01, this is equivalent to VIIRS becoming increasingly relatively brighter than MODIS; in this specific instance, it is thought that VIIRS is the more stable of the two sensors (B. Franz and G. Meister, personal communication, 2016). For the other bands, it is not clear at present which, or both, of the sensors is degrading. For VIIRS bands M07, M08, and M10 the change over the 5-year period exceeds $1 \%$ and so the temporal dependence is probably worth accounting for until residual trending of both sensors can be analysed and corrected for by the respective instrument teams. Stability of both sensors is monitored using the on-board solar diffuser and SDSM, as discussed previously. For the bands in question, additional polynomial detrending analyses were performed and implemented for the MODIS C6 reprocessing (Doelling et al., 2015); however, the most recent years of MODIS data had not yet been collected at that time, so it is possible that any additional degradation has deviated from these prior models.

The mission-averaged gain correction factors are shown in Table 3, along with (for bands M07, M08, and M10) linear trends. These trends were calculated from least-squares linear regression of the monthly gains with the time ordinate taken as years since the start of 1 January 2010, and the uncertainties presented with these parameters are the standard least-squares linear regression uncertainties. A linear model 
(a) $412 \mathrm{~nm}(\mathrm{M} 01)$

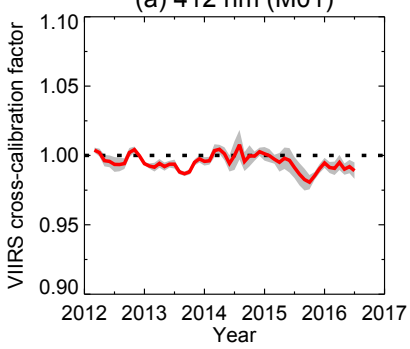

(e) $670 \mathrm{~nm}(\mathrm{M} 05)$

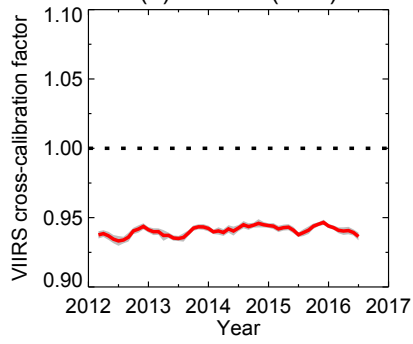

(i) $1610 \mathrm{~nm}$ (M10)

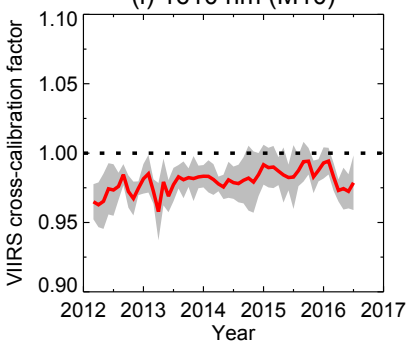

(b) $440 \mathrm{~nm}(\mathrm{M} 02)$

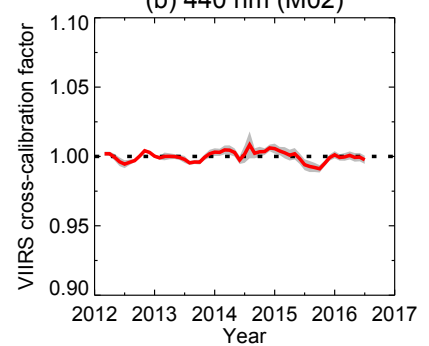

(f) $745 \mathrm{~nm}(\mathrm{M06})$

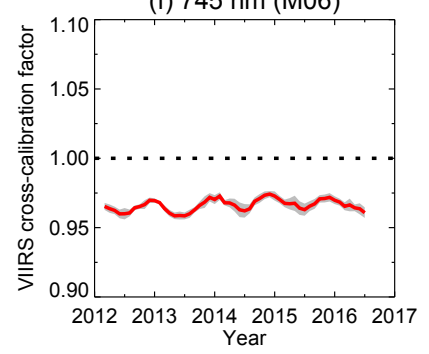

(j) $2250 \mathrm{~nm}(\mathrm{M} 11)$

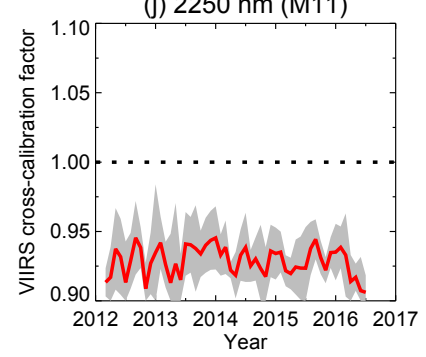

(c) $490 \mathrm{~nm}(\mathrm{M} 03)$

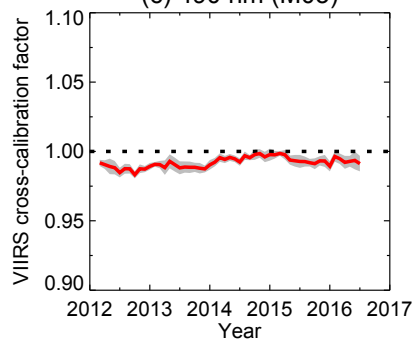

(g) $865 \mathrm{~nm}(\mathrm{M} 07)$
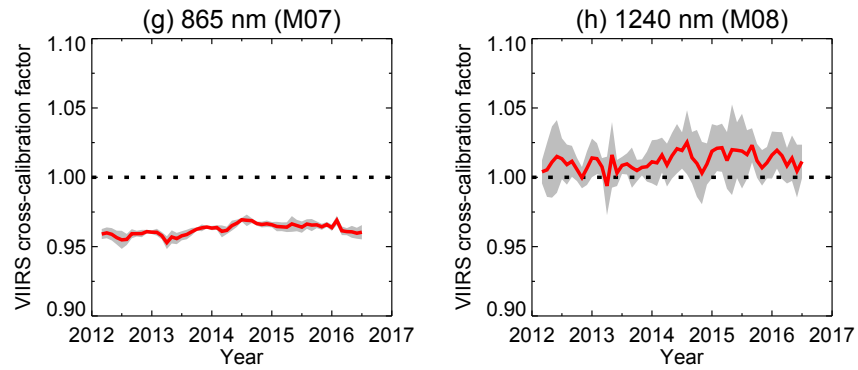

Figure 9. Time series of monthly mean VIIRS gain correction factors derived for each band (cf. Fig. 5). Red lines indicate the mean value for a month and the shaded grey area the standard deviation within a month.

was used based on visual examination of the data, although there is no particular reason to expect a linear change as opposed to any other specific functional form or that this behaviour will continue in years to come, so these trends should be interpreted with caution.

For the mission-averaged gains, the total uncertainty $\sigma_{\text {tot }}$ was estimated as the quadrature sum of four components:

$\sigma_{\text {tot }}^{2}=\sigma_{\text {temp }}^{2}+\sigma_{\text {het }}^{2}+\sigma_{\text {aer }}^{2}+\sigma_{\text {gas }}^{2}$.

These components were estimated as follows:

1. Temporal variability $\left(\sigma_{\text {temp }}\right)$ : this component was taken as the standard deviation of the monthly derived gains, and incorporates both the effects of changes in the gain with time, as well as noise in the monthly values (from e.g. sampling, residual errors in the radiative transfer or ancillary data).

2. Scene heterogeneity $\left(\sigma_{\text {het }}\right)$ : as noted previously, VIIRS $\mathrm{M}$ bands are at a finer spatial resolution than the MODIS data used in the matchfiles, and so the matchfiles contain both the mean and nearest-to-pixel-centre VIIRS reflectance within each MODIS pixel. The potential error from scene heterogeneity was assessed by performing the same analysis with both mean and nearestneighbour VIIRS reflectances and taking half the absolute difference in calculated gains between the two.

3. Aerosol model assumption $\left(\sigma_{\mathrm{aer}}\right)$ : as noted, restricting to open-ocean low-AOD scenes means that the dominant aerosol type is likely to be marine aerosols, and the assumption was made of a global-average $\mathrm{FMF}=0.4$. The uncertainty resulting from this assumption was estimated by repeating the whole analysis using $\mathrm{FMF}=0.2$ and 0.6 and taking half the absolute difference in the results.

4. Trace gas absorption assumption $\left(\sigma_{\text {gas }}\right)$ : this is estimated by considering the 68 th percentile of the absolute difference in the gain correction (on a monthly basis), which would result if the trace gas absorption correction for either sensor were systematically biased relative to the other sensor by $10 \%$ of the magnitude of the gas correction. The median of these monthly values is then reported as $\sigma_{\text {gas }}$ for each band, although the temporal variability is small. 
Table 3. Derived cross-calibration gain correction scaling factors. Mission-averaged gains are presented, as well as linear trends, for those bands where the estimated gain change over the mission to date is larger than $1 \%$ and statistically distinguishable from zero at the $90 \%$ confidence level. For the trends, times $t$ are defined in terms of years since 1 January 2010. Figures in parentheses indicate the 1 standard deviation uncertainty estimate.

\begin{tabular}{lcrr}
\hline VIIRS band & Gain correction & \multicolumn{2}{c}{ Linear trend parameters, $a+b t$} \\
& & $a$ & $b$ \\
\hline $412 \mathrm{~nm}(\mathrm{M} 01)$ & $0.995( \pm 0.006)$ & - & - \\
$440 \mathrm{~nm}(\mathrm{M} 02)$ & $1.000( \pm 0.004)$ & - & - \\
$490 \mathrm{~nm}(\mathrm{M} 03)$ & $0.992( \pm 0.004)$ & - & - \\
$550 \mathrm{~nm}(\mathrm{M} 04)$ & $0.956( \pm 0.009)$ & - & - \\
$670 \mathrm{~nm}(\mathrm{M} 05)$ & $0.941( \pm 0.008)$ & - & - \\
$745 \mathrm{~nm}(\mathrm{M} 06)$ & $0.966( \pm 0.005)$ & - & $0.0018( \pm 0.0003)$ \\
$865 \mathrm{~nm}(\mathrm{M} 07)$ & $0.963( \pm 0.004)$ & $0.9544( \pm 0.0016)$ & $0.0019( \pm 0.0006)$ \\
$1240 \mathrm{~nm}(\mathrm{M} 08)$ & $1.011( \pm 0.009)$ & $1.003( \pm 0.0029)$ & $0.0035( \pm 0.0007)$ \\
$1610 \mathrm{~nm}(\mathrm{M} 10)$ & $0.981( \pm 0.011)$ & $0.9646( \pm 0.0033)$ & 0.007 \\
$2250 \mathrm{~nm}(\mathrm{M} 11)$ & $0.931( \pm 0.018)$ & - & - \\
\hline
\end{tabular}

These uncertainty estimates are designed to be conservative; e.g. temporal standard deviation rather than standard error was used to calculate $\sigma_{\text {temp }}$ on the grounds that it is uncertain to what extent the uncertainties on individual monthly values are random vs. systematic. The temporal variability and gas components tend to be the dominant contributors in most bands. The term $\sigma_{\text {het }}$ is the smallest component for all bands.

Aside from bands M01 and M02 (no significant adjustment) and M08 (slight brightening), the effect of the crosscalibration is to darken the VIIRS channels by up to $\sim 7 \%$. There are no other results which are directly comparable with these since, as mentioned previously, prior analyses (Cao et al., 2013, 2014; Uprety et al., 2013, 2014; Uprety and Cao, 2015; Hlaing et al., 2014; Wang and Cao, 2016; B. Franz et al., personal communication, 2016) have used different versions of the L1 data (mostly, NOAA IDPS rather than NASA VCST baseline products), have considered only a subset of bands, and have in some cases exhibited contradictory results. Thus, some differences are expected. However, if these gain changes bring VIIRS measurements closer to the "truth", then this should ideally be reflected in the validation of geophysical data products applying these gains prior to their retrieval algorithms.

\section{Effect of calibration updates on AOD retrieval}

This section illustrates the results of applying the cross-calibration corrections in Table 3 (including timedependence, for the relevant bands) to VIIRS data and processing them through the SOAR retrieval algorithm to illustrate the effects on derived aerosol properties. The VIIRS application of SOAR will be described in a subsequent study, although it is basically an extension of the SeaWiFS application (Sayer et al., 2012a) to incorporate some of the additional features of VIIRS. Like many others, SOAR is a multispectral inversion using LUTs of physically based radiative transfer results (e.g. Stowe et al., 1997; Tanré et al., 1997; Mishchenko et al., 1999; Thomas et al., 2009; Sayer et al., 2010; Jackson et al., 2013). The algorithm uses VIIRS bands M03, M04, M05, M08, M08, M10, and M11 (i.e. 7 of the 10 bands analysed in this study) and provides AOD, FMF, and an indication of best-fit aerosol optical model at a nominal pixel size of $6 \times 6 \mathrm{~km}^{2}(8 \times 8 \mathrm{M}$-band pixels $)$. Spectral AOD is determined through the retrieved AOD at $550 \mathrm{~nm}$, together with the retrieved FMF and aerosol optical model. The specific details are of secondary importance here, as the main purpose is to illustrate the effects of the calibration change on the retrieval. To demonstrate these effects, the SOAR algorithm has been applied to VIIRS granules passing over six AERONET sites (Table 4), using the standard NASA L1b products with and without the cross-calibration gain corrections developed in this study. Comparing the AOD retrievals with AERONET enables a characterisation of both how much the spectral AOD retrieval is affected by the crosscalibration and whether these changes have improved the retrieval or not.

Note that SOAR is a multispectral inversion, fitting all bands simultaneously; the underlying radiative transfer is non-linear in AOD, and the bands are not weighted equally. As a result, changes in an individual band's calibration do not map linearly into retrieved AOD at a given wavelength, and it makes the most sense to analyse the behaviour of the retrieval system as a whole rather than attempt to assess or infer the effect of changes in AOD at a given wavelength to the calibration of individual bands. This is important to bear in mind when considering the results.

These sites have been chosen based on their locations (coastal/island AERONET sites with typically fairly low AODs, such that aerosol optical model assumptions will be less important contributors to the retrieval error characteristics) and the fact that, for at least part of the VIIRS mis- 
Table 4. Locations of the AERONET sites used and number of matchups obtained at each.

\begin{tabular}{lrrr}
\hline Site & Latitude $\left(^{\circ}\right)$ & Longitude $\left(^{\circ}\right)$ & $\begin{array}{r}\text { Number of } \\
\text { matchups }\end{array}$ \\
\hline ARM Graciosa & 39.091 & -28.029 & 138 \\
Ascension Island & -7.976 & -14.415 & 529 \\
Ersa & 43.004 & 9.359 & 981 \\
Manus & -2.060 & 147.425 & 86 \\
MCO Hanimaadhoo & 6.776 & 73.183 & 243 \\
Midway Island & 28.210 & -177.378 & 81 \\
\hline
\end{tabular}

sion, the sun photometers deployed at these sites included a $1640 \mathrm{~nm}$ filter so that AOD can be validated across the whole spectral range of bands used by SOAR-VIIRS with minimal extrapolation (the majority of AERONET sun photometers lack filters at wavelengths longer than $1020 \mathrm{~nm}$ ). The analysis protocol is the same as in Sayer et al. (2012a) and is described briefly here. AERONET provides point observations of spectral columnar AOD with a repeat frequency of approximately once per 10-15 min (in cloud-free conditions) and an uncertainty of order $0.01-0.02$, with the larger uncertainties at shorter wavelengths (Eck et al., 1999). To mitigate the effects of spatiotemporal aerosol variability on the comparison, AERONET Version 2 Level 2 (cloud-screened and quality-assured; Smirnov et al., 2000) observations are averaged over $\pm 30 \mathrm{~min}$ around the time of the VIIRS overpass and interpolated to the VIIRS M-band wavelengths using the spectrally closest AERONET AOD (with the exception that the AERONET $870 \mathrm{~nm}$ band is used in preference to $1020 \mathrm{~nm}$ due to increased uncertainties in the latter) and the Ångström exponent over the appropriate spectral region. Occasional missing AERONET AOD data at an individual wavelength are gap-filled in the same way. As it lies outside the AERONET spectral range, M11 $(2250 \mathrm{~nm})$ AOD is estimated from the AERONET AOD at $1640 \mathrm{~nm}$ and an Ångström exponent calculated over the spectral range 870$1640 \mathrm{~nm}$. This spectral interpolation/extrapolation introduces negligible additional uncertainty into the AERONET values. These AERONET AOD data are compared with averaged SOAR-VIIRS retrievals passing algorithm quality assurance checks (Sayer et al., 2012a) whose pixel central locations lie within $\pm 25 \mathrm{~km}$ of the AERONET site.

Figure 10 provides summary validation statistics for AOD at $550 \mathrm{~nm}$, composited across the AERONET sites. Using the standard L1 calibration the bias is 0.033, similar in magnitude to that of the NOAA VIIRS ocean AOD products (Huang et al., 2016); applying the cross-calibration gains removes a little over half of this bias (about 0.016) and also gives a root-mean-square (RMS) error smaller by about 0.01 . It additionally brings another $13 \%$ of matchups in agreement with AERONET to within the data set's expected level of uncertainty. The resulting bias on mid-visible AOD is similar to or smaller than preliminary validation results for the current
Collection 6 MODIS over-water AOD retrieval algorithm, which is conceptually similar to SOAR (Sayer et al., 2012c; Levy et al., 2013). The correlation coefficient is similar, indicating that the effect is more a shift in the AOD distribution than a change in the scatter. The total data volume changes slightly, as the calibration change affects cloud masking and quality assurance parts of the SOAR algorithm in the two runs (Sayer et al., 2012a).

Figure 11 presents some similar summary statistics, but for spectral AOD rather than AOD at $550 \mathrm{~nm}$. Only the points where both runs provide a valid matchup are considered in this figure (and these provide the counts listed in Table 4). Similar bias/RMS improvements, and negligible changes in correlation coefficient, are seen at other visible wavelengths. For the SWIR bands the change in AOD is smaller and there remains a residual positive bias of around 0.02. It is unclear to what extent this indicates problem with the retrieval forward model and/or MODIS Aqua's calibration, or calibration biases at individual AERONET sites (which are likely to be reasonably systematic, rather than random, for an individual site and individual deployment). Nevertheless, the cross-calibration results clearly improve the quality of the main retrieval data product (AOD at $550 \mathrm{~nm}$ ) and provide similar error statistics to the most similar available MODIS AOD product.

\section{Discussion}

Accurate and stable radiometric calibration is a necessary first step in creating a high-quality space-based data record of atmospheric aerosols, or indeed other geophysical variables. This is becoming increasingly important as there is potential to combine data records from multiple similar satellite sensors. This analysis has used near-coincident MODIS Aqua and S-NPP VIIRS observations of cloud-free openocean scenes to develop cross-calibration corrections for VIIRS M-band TOA reflectance, accounting for the differences between the sensors' spectral response functions and viewing geometries, to tie the VIIRS calibration to the MODIS standard. To be clear, these corrections represent scaling factors to apply to the NASA VIIRS L1 version 2 TOA reflectance/radiance data to make the bands radiatively consistent with MODIS Aqua, noting the fact that some differences are expected due to the differences in RSRs and only attempting to correct for the unexpected portion of the differences.

The analysis suggests that the standard NASA L1 (version 2.0) VIIRS reflectance data require scaling by between approximately +1 and $-7 \%$, depending on the band, to bring them into radiative consistency with MODIS Aqua, with indications of relative trending of up to $\sim 0.35 \%$ per year (over the March 2012-July 2016 time period analysed) in some bands. The relative contribution of the two sensors to these drifts in relative calibration is not yet clear. The precision of these gains is typically of order $0.5-1 \%$ for visible and NIR 
(a) Standard L1 calibration

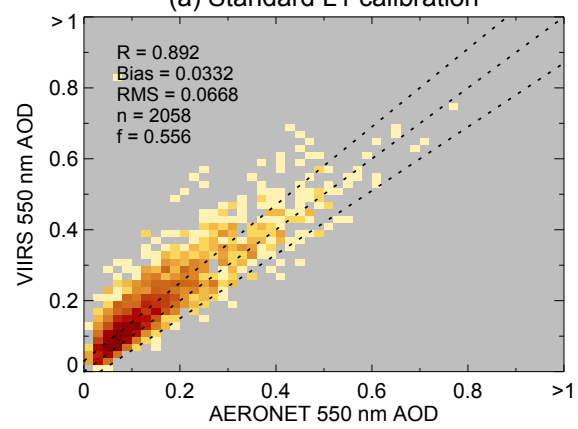

(b) With gain corrections

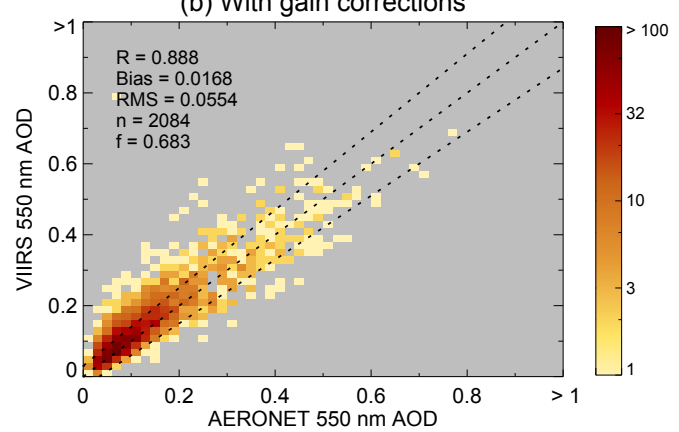

Figure 10. Statistics of SOAR-VIIRS $550 \mathrm{~nm}$ AOD validation against AERONET (a) without and (b) with the cross-calibration gains derived in the present study. Statistics are given on the panels: Pearson's linear correlation coefficient $R$, the median VIIRS-AERONET AOD bias, the root-mean-square (RMS) error, the number of matched points $n$, and the fraction of points $f$ in agreement with AERONET within $\pm(0.03+10 \%)$ Statistics are composites for all sites listed in Table 4 .

(a) Spectral AOD correlation

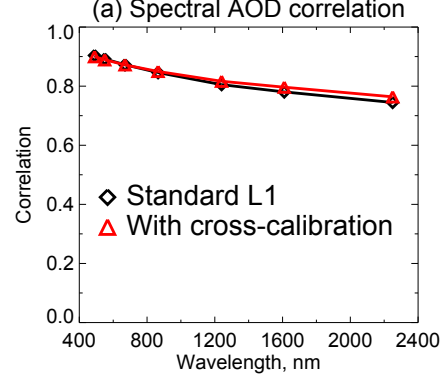

(b) Spectral AOD error

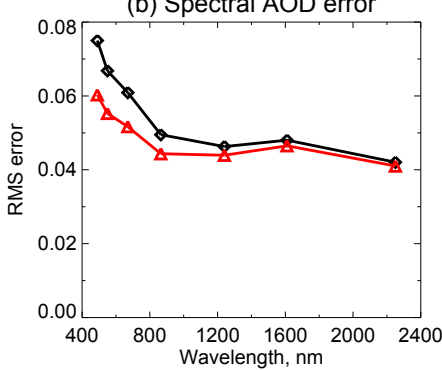

(c) Spectral AOD bias

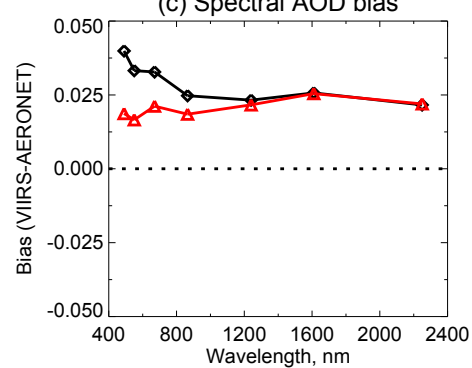

Figure 11. Statistics of SOAR-VIIRS spectral AOD validation against AERONET without (black) and with (red) the gain adjustments derived in the present study. Panels show (a) correlation coefficients, (b) root-mean-square AOD error, and (c) median AOD bias. Statistics are composites for all sites listed in Table 4.

bands and 1-2\% for SWIR bands due to a combination of trending and increased noise in the latter cases. Application of the cross-calibration gains to the SOAR algorithm, to derive spectral AOD over water pixels around six AERONET sites, illustrates that the calibration adjustments do provide an improvement in retrieved AOD in the visible spectral region (470-865 nm) although they do not address a bias in AOD retrieved at SWIR wavelengths.

Even if MODIS Aqua's calibration is imperfect, as any sensor's necessarily is, this analysis is consistent with prior indications that it is likely to be better than that of VIIRS. Importantly, obtaining radiatively consistent L1 data increases the likelihood of similar error statistics in downstream L2 data products, which facilitates the creation of long-term data records by combining individual sensors, by minimising discontinuities between products. Additionally, the analysis technique is independent of the AERONET validation data used to evaluate the AOD retrieval algorithms, so the effect of the calibration changes can be evaluated in a way that is not circular and also has the advantage that the gain corrections can be applied directly to other retrieval algorithms (i.e. errors in the SOAR algorithm or AERONET data are not aliased into the corrections). Further, the analysis can be easily repeated as additional versions of the source MODIS and VIIRS L1 data become available, to assess whether the offsets, and relative stability, of the sensors has changed. Conceptually it could also be applied to other sensors with frequent orbital overlaps - although, as seen in this analysis, even for sensors with nominally similar orbital overpass times, a shift in a few minutes can have a large effect on the data volume available for analysis.

Several caveats remain. The scenes analysed here (cloudfree oceans) are for brightnesses typical for aerosol retrievals, i.e. fairly dark, and detector non-linearities may mean that for very bright scenes (e.g. optically thick clouds or snow) the relative offsets between the two sensors may differ, particularly for the SWIR bands where the open-ocean signal is low. However, preliminary results from independent analysis of bright water clouds scenes provide largely consistent results, suggesting non-linearities are small (K. Meyer, personal communication, 2017). The use of binned data and robust statistics (medians) decreases the susceptibility to residual cloud contamination and other sources of outliers, although it is possible that these will make some residual contribution to the uncertainty. Another main caveat is that, while similar, VIIRS' and MODIS' spectral response func- 
tions are different, and these differences are large enough that the calibration exercise must involve the use of radiative transfer models, as the expected differences arising solely from these shifts in spectral response can be larger than the calibration corrections. The effects of this are more severe the more strongly the relevant sensor bands differ. This analysis has accounted for these spectral response differences, which is possible since the spectral dependence of atmospheric and surface scattering and absorption can be accounted for with high accuracy over these cloud-free lowaerosol oceanic scenes, although these differences do contribute to residual error and uncertainty in the derived calibration corrections. The well-calibrated hyperspectral Infrared Atmospheric Sounding Interferometer (IASI) has been used in the thermal IR domain to investigate the calibration and spectral response of other sensors (Sohn et al., 2010; Goldberg et al., 2011), as its hyperspectral bands can be combined to mimic closely the broader bands of MODIS and other sensors; there is no current equivalent, however, for the visible through to SWIR spectral domain. The proposed Climate Absolute Radiance and Refractivity Observatory (CLARREO) Reflected Solar Spectrometer (Wu et al., 2015), once available, will add this important capability.

Data availability. The source data sets used can be accessed via the links in the Acknowledgements or on the Assets tab. The VIIRS aerosol data products will be released to the public later in 2017; sample results are available from the authors on request.

Competing interests. The authors declare that they have no conflict of interest.

Acknowledgements. This work was supported by the NASA ROSES program and NASA's EOS program managed by Hal Maring. More information about the Deep Blue aerosol project can be found at http://deepblue.gsfc.nasa.gov. MCST and VCST are thanked for their efforts to maintain and improve the radiometric quality of MODIS and VIIRS data. The VIIRS Atmospheres SIPS at the University of Wisconsin (http://sips.ssec.wisc.edu; VIIRS Atmospheres SIPS, 2017), in particular S. Dutcher, are thanked for assistance and resources related to the creation of the matchfiles and Deep Blue processing support. The AERONET team and site PIs (P. Goloub, L. Gregory, B. Holben, M. Mallet, R. Wagener) are thanked for the creation and stewardship of the sun photometer data record; AERONET data are available from http://aeronet.gsfc.nasa.gov; (Nasa, 2017). GMAO are thanked for the meteorological data used in this analysis. The OBPG are thanked for useful insights and suggestions relating to an initial version of this analysis, as well as the creation of SeaWiFS chlorophyll products. D. Antoine (Curtin), B. A. Franz (NASA GSFC), Z. Lee (University of Massachusetts Boston), and A. Vasilkov (SSAI) are thanked for useful discussions and data sets about the current status of measurements of the optical properties of seawater and bidirectional aspects of remote sensing reflectance, and R. Spurr
(RT Solutions) for additional development of the VLIDORT RT code and interface. X. Xiong (NASA GSFC), K.-F. Chiang (SSAI), N. Lei (SSAI), A. Angal (SSAI), K. Meyer (NASA GSFC), C. Cao (NOAA), and A. Gilerson (CCNY/NOAA CRESST) are thanked for discussions about MODIS and VIIRS characterisation and spacecraft orbits. Data processing was facilitated by use of the GNU Parallel utility by Tange (2011). Two reviewers (F. C. Seidel and one anonymous) are acknowledged for helpful and constructive comments, which helped to improve the clarity of the manuscript.

Edited by: A. Kokhanovsky

Reviewed by: F. C. Seidel and one anonymous referee

\section{References}

Ahmad, Z., McClain, C. R., Herman, J. R., Franz, B. A., Kwiatkowska, E. J., Robinson, W. D., Buscela, E. J., and Tzortziou, M.: Atmospheric correction for NO2 absorption in retrieving water-leaving reflectances from the SeaWiFS and MODIS measurements, J. Quant. Spectrosc. Ra., 46, 6504-6512, doi:10.1364/AO.46.006504, 2007.

Ahmad, Z., Franz, B. A., McClain, C. R., Kwiatowska, E. J., Werdell, J., Shettle, E. P., and Holben, B. N.: New aerosol models for the retrieval of aerosol optical thickness and normalized water-leaving radiances from the SeaWiFS and MODIS sensors over coastal regions and open oceans, Appl. Opt., 49, 55455560, doi:10.1364/AO.49.005545, 2010.

Austin, R. W.: The remote sensing of spectral radiance from below the ocean surface, Optical Aspects of Oceanography, edited by: Jerlov, N. G. and Nielsen, E. S., Academic Press, 317-344, 1974.

Barnes, W. L., Pagano, T. S., and Salomonson, V. V.: Prelaunch characteristics of the Moderate Resolution Imaging Spectroradiometer (MODIS) on EOS-AM1, IEEE T. Geosci. Remote, 36, 1088-1100, doi:10.1109/36.700993, 1998.

Callaghan, A., de Leeuw, G., Cohen, L., and O'Dowd, C. D.: Relationship of oceanic whitecap coverage to wind speed and wind history, Geophys. Res. Lett., 35, L23609, doi:10.1029/2008GL036165, 2008.

Cao, C., Xiong, J., Blonski, S., Liu, Q., Uprety, S., Shao, X., Bai, Y., and Weng, F.: Suomi NPP VIIRS sensor data record verification, validation, and long-term performance monitoring, J. Geophys. Res., 118, 11664-11678, doi:10.1002/2013JD020418, 2013.

Cao, C., De Luccia, F. J., Xiong, X., Wolfe, R., and Weng, F.: Early On-Orbit Performance of the Visible Infrared Imaging Radiometer Suite Onboard the Suomi National Polar-Orbiting Partnership (S-NPP) Satellite, IEEE T. Geosci. Remote, 52, 1142-1156, doi:10.1109/TGRS.2013.2247768, 2014.

Clough, S. A., Shephard, M. W., Mlawer, E. J., Delamere, J. S., Iacono, M. J., Cady-Pereira, K., Boukabara, S., and Brown, P. D.: Atmospheric radiative transfer modeling: a summary of the AER codes, J. Quant. Spectrosc. Ra., 91, 233-244, doi:10.1016/j.jqsrt.2004.05.058, 2005.

Cox, C. and Munk, W.: Measurement of the roughness of the sea surface from photographs of the Sun's glitter, J. Opt. Soc. Am., 44, 838-850, doi:10.1364/JOSA.44.000838, 1954a.

Cox, C. and Munk, W.: Statistics of the sea surface derived from Sun glitter, J. Mar. Res., 13, 198-227, 1954b. 
Doelling, D. R., Wu, A., Xiong, X., Scarino, B. R., Bhatt, R., Haney, C. O., Morstad, D., and Gopalan, A.: The Radiometric Stability and Scaling of Collection 6 Terra- and Aqua-MODIS VIS, NIR, and SWIR Spectral Bands, IEEE T. Geosci. Remote, 53, 45204535, doi:10.1109/TGRS.2015.2400928, 2015.

Dubovik, O. and King, M. D.: A flexible inversion algorithm for retrieval of aerosol optical properties from Sun and sky radiance measurements, J. Geophys. Res., 105, 20673-20696, doi:10.1029/2000JD900282, 2000.

Eck, T. F., Holben, B. N., Reid, J. S., Dubovik, O., Smirnov, A., O'Neill, N. T., Slutsker, I., and Kinne, S.: Wavelength dependence of the optical depth of biomass burning, urban, and desert dust aerosols, J. Geophys. Res., 104, 31333-31349, 1999.

Franz, B. A., Bailey, S. W., Werdell, P. J., and McClain, C. R.: Sensor-independent approach to the vicarious calibration of satellite ocean color radiometry, Appl. Opt., 46, 5068-5082, doi:10.1364/AO.46.005068, 2007.

Frey, R. A., Ackerman, S. A., Liu, Y., Strabala, K. I., Zhang, H., Key, J. R., and Wang, X.: Cloud Detection with MODIS, Part I: Improvements in the MODIS Cloud Mask for Collection 5., J. Atmos. Ocean. Tech., 25, 1057-1072, doi:10.1175/2008JTECHA1052.1, 2008.

Goldberg, M., Ohring, G., Butler, J., Cao, C., Datla, R., Doelling, D., Gaertner, V., Hewison, T., Iacovazzi, B., Kim, D., Kurino, T., Lafeuille, J., Minnis, P., Renaut, D., Schmetz, J., Tobin, D., Wang, L., Weng, F., Wu, X., Yu, F., Zhang, P., and Zhu, T.: The Global Space-based Inter-Calibration System (GSICS), B. Am. Meteorol. Soc., 92, 467-475, doi:10.1175/2010BAMS2967.1, 2011.

Gueymard, C.: SMARTS2: a simple model of the atmospheric radiative transfer of sunshine: algorithms and performance assessment, Tech. rep., Florida Solar Energy Center, 1995.

Hale, G. M. and Querry, M. R.: Optical constants of water in the 200-nm to 200- $\mu \mathrm{m}$ wavelength region, Appl. Opt., 12, 555-563, doi:10.1364/AO.12.000555, 1973.

Hess, M., Koepke, P., and Schult, I.: Optical properties of aerosols and clouds: The software package OPAC, B. Am. Meteorol. Soc., 79, 831-944, doi:10.1175/15200477(1998)079<0831:OPOAAC>2.0.CO;2, 1998.

Hlaing, S., Gilerson, A., Foster, R., Wang, M., Arnone, R., and Ahmed, S.: Radiometric calibration of ocean color satellite sensors using AERONET-OC data, Opt. Express, 22, 23385-23401, doi:10.1364/OE.22.023385, 2014.

Holben, B. N., Eck, T. F., Slutsker, I., Tanré, D., Buis, J. P., Setzer, A., Vermote, E., Reagan, J. A., Kaufman, Y. J., Nakajima, T., Lavenu, F., Jankowiak, I., and Smirnov, A.: AERONET: A federated instrument network and data archive for aerosol characterization, Remote Sens. Environ., 66, 1-16, doi:10.1016/S00344257(98)00031-5, 1998.

Hsu, N. C., Tsay, S.-C., King, M. D., and Herman, J. R.: Aerosol properties over bright-reflecting source regions, IEEE T. Geosci. Remote, 42, 557-569, doi:10.1109/TGRS.2004.824067, 2004.

Hsu, N. C., Jeong, M.-J., Bettenhausen, C., Sayer, A. M., Hansell, R., Seftor, C. S., Huang, J., and Tsay, S.-C.: Enhanced Deep Blue Aerosol Retrieval Algorithm: the second Generation, J. Geophys. Res., 118, 9296-9315, doi:10.1002/jgrd.50712, 2013.

Huang, J., Kondragunta, S., Laszlo, I., Liu, H., Remer, L. A., Zhang, H., Superczynski, S., Ciren, P., Holben, B. N., and Petrenko, M.: Validation and expected error estimation of Suomi-
NPP VIIRS aerosol optical thickness and Ångström exponent with AERONET, J. Geophys. Res.-Atmos., 120, 7139-7160, doi:10.1002/2016JD024834, 2016.

Jackson, J. M., Liu, H., Laszlo, I., Kondragunta, S., Remer, L. A., Huang, J., and Huang, H.-C.: Suomi-NPP VIIRS aerosol algorithms and data products, J. Geophys. Res., 118, 12673-12689, doi:10.1002/2013JD020449, 2013.

Jeong, M.-J., Hsu, N. C., Kwiatkowska, E. J., Franz, B. A., Meister, G., and Salustro, C. E.: Impacts of Cross-Platform Vicarious Calibration on the Deep Blue Aerosol Retrievals for Moderate Resolution Imaging Spectroradiometer Aboard Terra, IEEE T. Geosci. Remote, 49, 4877-4988, doi:10.1109/TGRS.2011.2153205, 2011.

Jethva, H., Torres, O., Remer, L. A., and Bhartia, P. K.: A Color Ratio Method for Simultaneous Retrieval of Aerosol and Cloud Optical Thickness of Above-Cloud Absorbing Aerosols From Passive Sensors: Application to MODIS Measurements, IEEE T. Geosci. Remote, 51, 3862-3870, doi:10.1109/TGRS.2012.2230008, 2013.

Kahn, R. A., Sayer, A. M., Ahmad, Z., and Franz, B. A.: The Sensitivity of SeaWiFS Ocean Color Retrievals to Aerosol Amount and Type, J. Atmos. Ocean. Tech., 33, 1185-1209, doi:10.1175/JTECH-D-15-0121.1, 2016.

Koepke, P.: Effective reflectance of oceanic whitecaps, Appl. Opt., 23, 1816-1824, doi:10.1364/AO.23.001816, 1984.

Lee, T. E., Miller, S. D., Turk, F. J., Schueler, C., Julian, R., Deyo, S., Dills, P., and Wang, S.: The NPOESS VIIRS Day/Night Visible Sensor, B. Am. Meteorol. Soc., 87, 191-199, doi:10.1175/BAMS-87-2-191, 2006.

Lee, Z., Carder, K. L., Mobley, C. D., Steward, R. G., and Patch, J. S.: Hyperspectral remote sensing for shallow waters. I. A semianalytical model, Appl. Opt., 37, 6329-6338, doi:10.1364/AO.37.006329, 1998.

Lee, Z., Wei, J., Voss, K., Lewis, M., Bricaud, A., and Huot, Y.: Hyperspectral absorption coefficient of "pure" seawater in the range of 350-550 $\mathrm{nm}$ inverted from remote sensing reflectance, Appl. Opt., 54, 546-558, doi:10.1364/AO.54.000546, 2015.

Lei, N. and Xiong, X.: Products of the SNPP VIIRS SD Screen Transmittance and the SD BRDFs From Both Yaw Maneuver and Regular On-Orbit Data, IEEE T. Geosci. Remote, 55, 19751987, doi:10.1109/TGRS.2016.2633967, 2017.

Levy, R. C., Remer, L. A., and Kaufman, Y. J.: Effects of neglecting polarization on the MODIS aerosol retrieval over land, IEEE T. Geosci. Remote, 42, 2576-2583, doi:10.1109/TGRS.2004.837336, 2004.

Levy, R. C., Remer, L. A., Mattoo, S., Vermote, E. F., and Kaufman, Y. J.: Second-generation operational algorithm: Retrieval of aerosol properties over land from inversion of Moderate Resolution Imaging Spectroradiometer spectral reflectance, J. Geophys. Res., 112, doi:10.1029/2006JD007811, 2007.

Levy, R. C., Mattoo, S., Munchak, L. A., Remer, L. A., Sayer, A. M., Patadia, F., and Hsu, N. C.: The Collection 6 MODIS aerosol products over land and ocean, Atmos. Meas. Tech., 6, 29893034, doi:10.5194/amt-6-2989-2013, 2013.

Levy, R. C., Munchak, L. A., Mattoo, S., Patadia, F., Remer, L. A., and Holz, R. E.: Towards a long-term global aerosol optical depth record: applying a consistent aerosol retrieval algorithm to MODIS and VIIRS-observed reflectance, Atmos. Meas. Tech., 8, 4083-4110, doi:10.5194/amt-8-4083-2015, 2015. 
Liu, H., Remer, L. A., Huang, J., Huang, H.-C., Kondragunta, S., Laszlo, I., Oo, M., and Jackson, J. M.: Preliminary evaluation of S-NPP VIIRS aerosol optical thickness, J. Geophys. Res., 119, 3942-3962, doi:10.1002/2013JD020360, 2014.

Lyapustin, A., Wang, Y., Laszlo, I., Kahn, R., Korkin, S., Remer, L., Levy, R., and Reid, J. S.: Multiangle implementation of atmospheric correction (MAIAC): 2. Aerosol algorithm, J. Geophys. Res., 116, D03211, doi:10.1029/2010JD014986, 2011.

Lyapustin, A., Wang, Y., Xiong, X., Meister, G., Platnick, S., Levy, R., Franz, B., Korkin, S., Hilker, T., Tucker, J., Hall, F., Sellers, P., Wu, A., and Angal, A.: Scientific impact of MODIS C5 calibration degradation and C6+ improvements, Atmos. Meas. Tech., 7, 4353-4365, doi:10.5194/amt-7-4353-2014, 2014.

Meister, G. and Franz, B. A.: Adjustments to the MODIS Terra radiometric calibration and polarization sensitivity in the 2010 reprocessing, in: Proceedings of SPIE, 8153, doi:10.1117/12.891787, 2011.

Meister, G., Kwiatkowska, E. J., Franz, B. A., Patt, F. S., Feldman, G. C., and McClain, C. R.: Moderate-Resolution Imaging Spectroradiometer ocean color polarization correction, Appl. Opt., 44, 5524-5535, doi:10.1364/AO.44.005524, 2005.

Mishchenko, M. I., Geogdzhayez, I. V., Cairns, B., Rossow, W. B., and Lacis, A. A.: Aerosol retrievals over the ocean by use of channels 1 and 2 AVHRR data: sensitivity analysis and preliminary results, Appl. Opt., 38, 7325-7341, doi:10.1364/AO.38.007325, 1999.

Monahan, E. C. and Muircheartaigh, I. O.: Optimal power-law description of oceanic whitecap coverage dependence on wind speed, J. Phys. Oceanogr., 10, 2094-2099, doi:10.1175/15200485(1980)010<2094:OPLDOO>2.0.CO;2, 1980.

Morel, A. and Prieur, L.: Analysis of variations in ocean color, Limnol. Oceanogr., 22, 709-722, 1977.

Morel, A., Antoine, D., and Gentili, B.: Bidirectional reflectance of oceanic waters: accounting for Raman emission and varying particle scattering phase function, Appl. Opt., 41, 6289-6306, doi:10.1364/AO.41.006289, 2002.

NASA: AERONET level 2 version 2 direct-Sun data available at: https://aeronet.gsfc.nasa.gov, last access: 10 April 2017.

O'Dowd, C. D. and de Leeuw, G.: Marine aerosol production: a review of the current knowledge, Philos. T. R. Soc. A, 365, 17531774, doi:10.1098/rsta.2007.2043, 2007.

Pope, R. M. and Fry, R. S.: Absorption spectrum (380-700 nm) of pure water, II. Integrating cavity measurements, Appl. Opt., 36, 8710-8723, doi:10.1364/AO.36.008710, 1997.

Sayer, A. M., Thomas, G. E., and Grainger, R. G.: A sea surface reflectance model for (A)ATSR, and application to aerosol retrievals, Atmos. Meas. Tech., 3, 813-838, doi:10.5194/amt-3813-2010, 2010.

Sayer, A. M., Hsu, N. C., Bettenhausen, C., Ahmad, Z., Holben, B. N., Smirnov, A., Thomas, G. E., and Zhang, J.: SeaWiFS Ocean Aerosol Retrieval (SOAR): Algorithm, validation, and comparison with other data sets, J. Geophys. Res., 117, D03206, doi:10.1029/2011JD016599, 2012a.

Sayer, A. M., Smirnov, A., Hsu, N. C., and Holben, B. N.: A pure marine aerosol model, for use in remote sensing applications, J. Geophs. Res., 117, D05213, doi:10.1029/2011JD016689, 2012b.

Sayer, A. M., Smirnov, A., Hsu, N. C., Munchak, L. A., and Holben, B. N.: Estimating marine aerosol particle volume and number from Maritime Aerosol Network data, Atmos. Chem. Phys., 12, 8889-8909, doi:10.5194/acp-12-8889-2012, 2012c.

Sayer, A. M., Hsu, N. C., and Bettenhausen, C.: Implications of MODIS bow-tie distortion on aerosol optical depth retrievals, and techniques for mitigation, Atmos. Meas. Tech., 8, 52775288, doi:10.5194/amt-8-5277-2015, 2015a.

Sayer, A. M., Hsu, N. C., Bettenhausen, C., Jeong, M.-J., and Meister, G.: Effect of MODIS Terra radiometric calibration improvements on Collection 6 Deep Blue aerosol products: Validation and Terra/Aqua consistency, J. Geophys. Res.-Atmos., 120, 12157-12174, doi:10.1002/2015JD023878, 2015 b.

Sayer, A. M., Hsu, N. C., Bettenhausen, C., Lee, J., Redemann, J., Schmid, B., and Shinozuka, Y.: Extending "Deep Blue" aerosol retrieval coverage to cases of absorbing aerosols above clouds: Sensitivity analysis and first case studies, J. Geophys. Res.Atmos., 121, 4830-4854, doi:10.1002/2015JD024729, 2016.

Smirnov, A., Holben, B. N., Eck, T. F., Dubovik, O., and Slutsker, I.: Cloud-screening and quality control algorithms for the AERONET database, Remote Sens. Environ., 73, 337-349, doi:10.1016/S0034-4257(00)00109-7, 2000.

Smirnov, A., Holben, B. N., Giles, D. M., Slutsker, I., O’Neill, N. T., Eck, T. F., Macke, A., Croot, P., Courcoux, Y., Sakerin, S. M., Smyth, T. J., Zielinski, T., Zibordi, G., Goes, J. I., Harvey, M. J., Quinn, P. K., Nelson, N. B., Radionov, V. F., Duarte, C. M., Losno, R., Sciare, J., Voss, K. J., Kinne, S., Nalli, N. R., Joseph, E., Krishna Moorthy, K., Covert, D. S., Gulev, S. K., Milinevsky, G., Larouche, P., Belanger, S., Horne, E., Chin, M., Remer, L. A., Kahn, R. A., Reid, J. S., Schulz, M., Heald, C. L., Zhang, J., Lapina, K., Kleidman, R. G., Griesfeller, J., Gaitley, B. J., Tan, Q., and Diehl, T. L.: Maritime aerosol network as a component of AERONET - first results and comparison with global aerosol models and satellite retrievals, Atmos. Meas. Tech., 4, 583-597, doi:10.5194/amt-4-583-2011, 2011.

Smith, R. C. and Baker, K. S.: Optical properties of the clearest natural waters $(200-800 \mathrm{~nm})$, Appl. Opt., 20, 177-184, doi:10.1364/AO.20.000177, 1981.

Sohn, B. J., Kim, B.-R., and Lee, S.-S.: Possible shift of spectral response function of the MODIS $6.8 \mu \mathrm{m}$ water vapor channel causing a cold bias of 2-3 K, Atmos. Meas. Tech., 3, 1667-1672, doi:10.5194/amt-3-1667-2010, 2010.

Spurr, R. J. D.: VLIDORT: A linearized pseudo-spherical vector discrete ordinate radiative transfer code for forward model and retrieval studies in multilayer multiple scattering media, J. Quant. Spectrosc. Ra., 102, 316-342, doi:10.1016/j.jqsrt.2006.05.005, 2006.

Stowe, L., Ignatov, A., and Singh, R.: Development, validation, and potential enhancements to the second-generation operational aerosol product at NOAA/NESDIS, J. Geophys. Res., 102, 16923-16934, 1997.

Sun, J., Xiong, X., Barnes, W., and Guenther, B.: MODIS Reflective Solar Bands On-Orbit Lunar Calibration, IEEE T. Geosci. Remote, 45, 2383-2393, doi:10.1109/TGRS.2007.896541, 2007.

Tange, O.: GNU Parallel - the command-line power tool, The USENIX Magazine, 42-47, 2011.

Tanré, D., Holben, B. N., and Kaufman, Y. J.: Atmospheric Correction Algorithm for NOAA-AVHRR Products: Theory and Application, IEEE T. Geosci. Remote, 30, 231-248, doi:10.1109/36.134074, 1992. 
Tanré, D., Kaufman, Y. J., Herman, M., and Mattoo, S.: Remote sensing of aerosol properties over oceans using the MODIS/EOS spectral radiances, J. Geophys. Res., 102, 1697116988, doi:10.1029/96JD03437, 1997.

Thomas, G. E., Poulsen, C. A., Sayer, A. M., Marsh, S. H., Dean, S. M., Carboni, E., Siddans, R., Grainger, R. G., and Lawrence, B. N.: The GRAPE aerosol retrieval algorithm, Atmos. Meas. Tech., 2, 679-701, doi:10.5194/amt-2-679-2009, 2009.

Toller, G., X., X., Sun, J., Wenny, B. N., Geng, X., Kuyper, J., Angal, A., Chen, H., Madhavan, S., and Wu, A.: Terra and Aqua Moderate-Resolution Imaging Spectroradiometer collection 6 level 1B algorithm, J. Appl. Remote Sens., 7, doi:10.1117/1.JRS.7.073557, 2013.

Uprety, S. and Cao, C.: Suomi NPP VIIRS reflective solar band onorbit radiometric stability and accuracy assessment using desert and Antarctica Dome C sites, Remote Sens. Environ., 166, 106115, doi:10.1016/j.rse.2015.05.021, 2015.

Uprety, S., Cao, C., Xiong, X., Blonski, S., Wu, A., and Shao, X.: Radiometric Intercomparison between Suomi-NPP VIIRS and Aqua MODIS Reflective Solar Bands Using Simultaneous Nadir Overpass in the Low Latitudes, J. Atmos. Ocean. Tech., 30, 2720-2736, doi:10.1175/JTECH-D-13-00071.1, 2013.

Uprety, S., Cao, C., Blonski, S., and Wang, W.: Assessment of VIIRS radiometric performance using vicarious calibration sites, in: Proceedings of SPIE, 9218, doi:10.1117/12.2061855, 2014.

Vasilkov, A. P., Herman, J. R., Ahmad, Z., Karu, M., and Mitchell, B. G.: Assessment of the ultraviolet radiation field in ocean waters from space-based measurements and full radiative-transfer calculations, Appl. Opt., 44, 2863-2869, doi:10.1364/AO.44.002863, 2005.

VIIRS Atmospheres SIPS: VIIRS/MODIS matchfiles, University of Wisconsin available at: http://sips.ssec.wisc.edu, last access: 10 April 2017.

Wang, J., Xu, X., Ding, S., Zeng, J., Spurr, R., Liu, X., Chance, K., and Mishchenko, M.: A numerical testbed for remote sensing of aerosols, and its demonstration for evaluating retrieval synergy from a geostationary satellite constellation of GEOCAPE and GOES-R, J. Quant. Spectrosc. Ra., 146, 510-528, doi:10.1016/j.jqsrt.2014.03.020, 2014.
Wang, W. and Cao, C.: Monitoring the NOAA Operational VIIRS RSB and DNB Calibration Stability Using Monthly and SemiMonthly Deep Convective Clouds Time Series, Remote Sens., 8, 32, doi:10.3390/rs8010032, 2016.

Wolfe, R. E., Lin, G., Nishihama, M., Tewari, K. P., and Montano, E.: NPP VIIRS early on-orbit geometric performance, in: Proceedings of SPIE, 8510, doi:10.1117/12.929925, 2012.

Wolfe, R. E., Lin, G., Nishihama, M., Tewari, K. P., Tilton, J. C., and Isaacman, A. R.: Suomi NPP VIIRS prelaunch and on-orbit geometric calibration and characterization, J. Geophys. Res.-Atmos., 118, 11508-11521, doi:10.1002/jgrd.50873, 2013.

Wu, A., Xiong, X., Jin, A., Lukashin, C., Wenny, B. N., and Butler, J. J.: Sensitivity of Intercalibration Uncertainty of the CLARREO Reflected Solar Spectrometer Features, IEEE T. Geosci. Remote, 53, 4741-4751, doi:10.1109/TGRS.2015.2409030, 2015.

Wu, A. S., Xiong, X. X., Doelling, D. R., Morstad, D., Angal, A., and Bhatt, R.: Characterization of Terra and Aqua MODIS VIS, NIR, and SWIR Spectral Bands' Calibration Stability, IEEE T. Geosci. Remote, 51, 4330-4338, doi:10.1109/TGRS.2012.2226588, 2013.

Xiong, X., Butler, J., Chiang, K., Efremova, B., Fulbright, J., Lei, N., McIntire, J., Oudrari, H., Wang, Z., and Wu, A.: Assessment of S-NPP VIIRS On-Orbit Radiometric Calibration and Performance, Remote Sens., 8, 84, doi:10.3390/rs8020084, 2016.

Zhang, X., Hu, L., and He, M.-X.: Scattering by pure seawater: Effect of salinity, Opt. Express., 17, 5698-5710, doi:10.1364/OE.17.005698, 2009. 